\title{
Extension of unsaturated soil mechanics and its applications
}

\section{Atsushi lizuka}

Professor, Research Center for Urban Safety and Security, Kobe University, Kobe, Japan (corresponding author: iizuka@kobe-u.ac.jp)

(Orcid:0000-0003-1241-1096)

Shinya Tachibana

Associate Professor, Research Center for Urban Safety and Security, Kobe University, Kobe, Japan

\section{Tomohide Takeyama}

Associate Professor, Civil Engineering Department, Graduate School of Engineering, Kobe University, Kobe, Japan

\author{
Yuri Sugiyama \\ Research Engineer, Port and Airport Research Institute, Yokosuka, Japan \\ Shun Nomura \\ Research Engineer, Japan Agency for Marine Science and Technology, \\ Yokosuka, Japan \\ Hideki Ohta \\ Professor, Research and Development Initiative, Chuo University, \\ Tokyo, Japan
}

Although the soil, water and air coupling theory has been deductively derived from the three-phase mixture theory, assumptions and interpretations inherent in soil mechanics are also conveniently introduced in this theory. Mechanical properties of unsaturated soils are phenomenologically integrated into the constitutive equation for a deformation problem, with effective stress expressed as a combination of partial stresses acting on each phase of the mixture. The governing equations of two seepage problems describing the movements of pore water and pore air are formulated by a priori introduction of Darcy's law. Consequently, the coupling theory consists of a deformation problem and two seepage problems, in which the soil-water retention characteristics play the role of a mediator connecting these problems. If the theoretical structure is clarified in this way, an extension of this theory is easily made. In this paper, the extension of the theory to each of four examples and their performance is demonstrated. The features of settlement caused by absorption of soil water due to vegetation; dissolution, advection and diffusion of substances in groundwater; desaturation and state change due to vaporisation of dissolved gas from pore water; and the liquefaction potential of unsaturated soil are presented.

\section{Notation}

1 second-order identity tensor

A fourth-order deviatoric tensor defined by $\boldsymbol{A}=\boldsymbol{I}-(1 / 3)(\mathbf{1} \otimes \mathbf{1})$

b

$b_{\mathrm{r}}$

$\boldsymbol{b}_{\alpha}$

$c^{\mathrm{e}}$

$c^{\text {ep }}$

c

$c_{\alpha}$

D

e

G

$G_{\mathrm{s}}$

$h_{\mathrm{a}}$

$h_{\mathrm{w}}$

I

J

K

$K_{\text {se }}$

$k_{\mathrm{a}}$

$k_{\mathrm{h}}$

$k_{\mathrm{W}}$

M body force working to the whole mixture

parameter which controls the rotational rate of the yield surface

body force working to the $\alpha$ phase

elastic stiffness tensor

elasto-plastic stiffness tensor

concentration ratio

parameter which controls the moving rate of the

similarity centre

diffusion coefficient

void ratio

shear modulus

specific gravity of soil particle

total air head

total water head

fourth-order identity tensors

concentration flux

bulk modulus

bulk modulus at the unsaturated state

coefficient of pore air permeability

Henry's constant $\left(\mathrm{mol} /\left(\mathrm{m}^{3} \mathrm{kPa}\right)\right)$

coefficient of pore water permeability

critical state parameter
$M_{\mathrm{c}} \quad$ mass of the dissolved solute

$M_{\mathrm{d}} \quad$ parameter which defines the boundary between the hardening and softening

$M_{\mathrm{f}} \quad$ mass of solution pore water

$M_{\mathrm{m}} \quad$ material molar mass $(\mathrm{g} / \mathrm{mol})$

$M_{\mathrm{r}} \quad$ parameter which defines the rotational limit of the yield surface

$M_{\mathrm{w}} \quad$ mass of solvent

$m \quad$ Mualem's constant (Mualem, 1976)

$m_{\mathrm{dg}} \quad$ mass of dissolved gas

$n \quad$ porosity

$n_{\mathrm{E}} \quad$ parameter for adjusting the rate of dilatancy development

$p^{\prime} \quad$ effective mean stress

$p_{\mathrm{a}} \quad$ pore air pressure

$p_{\mathrm{a}_{0}} \quad$ atmospheric pressure

$p_{\mathrm{c}}^{\prime} \quad$ effective mean stress at the pre-consolidation state

$p_{\text {sat }}^{\prime} \quad$ effective mean stress at the pre-consolidation state under saturated conditions

$p_{\mathrm{w}} \quad$ pore water pressure

$R \quad$ gas constant $(\mathrm{J} /(\mathrm{K} \mathrm{mol}))$

$S_{\mathrm{e}} \quad$ effective degree of saturation

$S_{\mathrm{r}} \quad$ degree of saturation

$S \quad$ suction

T absolute temperature (K)

$t$ time

$v_{\mathrm{g}} \quad$ velocity of the gas phase 
$v_{\mathrm{S}}$

\section{$\varepsilon$}

$\varepsilon^{\mathrm{e}}$

$\rho_{\alpha}\left(x_{\alpha}, \mathrm{t}\right)$ density of the $\alpha$ phase itself

$\bar{\rho}_{\alpha}\left(\boldsymbol{x}_{\alpha}, \mathrm{t}\right)$ density of the $\alpha$ phase in the whole mixture

\section{$\boldsymbol{\sigma}$}

$\boldsymbol{\sigma}^{\mathrm{N}} \quad$ net stress tensor

$\boldsymbol{\sigma}^{S_{\mathrm{r}}} \quad$ stress term tensor arising from the change of the degree of saturation

$\rho_{\mathrm{dg}} \quad$ density of the substantial part of the air dissolved in the liquid phase

$\bar{\rho}_{\mathrm{dg}} \quad$ density of the dissolved air per unit volume of the unsaturated soil

$\rho_{\mathrm{g}} \quad$ density of pore air (gas)

$\chi \quad$ Bishop's parameter

\section{Introduction}

If the construction of earth structures is regarded as an artificial mechanical action using soil materials, then unsaturated soil mechanics is the basic logical tool guiding the thinking process. According to Sheng (2011), the following three points should be considered in the theoretical framework for unsaturated soil mechanics: (a) volume change behaviour associated with suction or saturation change, $(b)$ shear strength behaviour associated with suction or saturation change and (c) hydraulic behaviour associated with suction or saturation change. Points $(a)$ and $(b)$ are considered in the constitutive equation, described as a relation between strain and effective stress. The expression of effective stress is another key point in describing the mechanical behaviour of unsaturated soils. The Bishop-type equation, which can be regarded as an extension of Terzaghi's equation for saturated soils, is also widely employed. Furthermore, many constitutive equations for unsaturated soils have been proposed since the pioneering work by Alonso et al. (1990). Constitutive modelling for unsaturated soils is reviewed in state-of-the-art reports, as exemplified by the publications by Gens (1996), Wheeler and Karube (1996), Kohgo (2003), Gens et al. (2008), Sheng and Fredlund (2008), Sheng et al. (2008) and Cui and Sun (2009), among others. Point (c) is expressed by the soil-water retention characteristic (SWRC) curve, which is formulated as the dependency of degree of saturation on suction. Since the mechanical behaviour of unsaturated soils depends on the degree of saturation - for example, as reported by Wheeler et al. (2003) - the implementation of SWRCs in describing the mechanical behaviour of unsaturated soils is quite an important issue. Almost all of the models of SWRCs are developed by referring to the works of Brooks and Corey (1964), van Genuchten (1980), Campbell (1987), Kosugi (1994) and Fredlund and Xing (1994), among others. Under these theoretical frameworks, many applications to geotechnical problems are made in the field of engineering - for example, the studies by Jommi (2013) and Iizuka and Tachibana (2017).

This paper presents some trials to extend the theory of unsaturated soil mechanics to applications to boundary value problems. After summarising the theoretical framework of unsaturated soil mechanics based on the three-phase mixture theory, unsaturated soil mechanics is understood simply as a coupled formulation of a deformation problem and two seepage problems. This articulation highlights the constitutive equation in the deformation problem with the use of Darcy's law in the dynamics of pore water and pore air flow.

\section{Theoretical framework of unsaturated soil mechanics}

The three-phase mixture theory is summarised in Figure 1. Governing equations are determined from the conservation laws for each phase with respect to the mixture. The stress acting on the mixture is balanced with the partial stresses acting on each phase, and the motion (deformation) of each phase is determined through the interaction forces between the phases - that is, in the case of a three-phase mixture, the motion (deformation) is determined in a field consisting of three mass conservation equations, three equations of motion and stress symmetry and three constitutive relational equations.

In soil mechanics, the stress component that contributes to the deformation of the structural skeleton of the soil is called the effective stress, and traditionally it originated from Terzaghi's equation for the saturated soil. In the case of unsaturated soils, Bishop's equation, which can be regarded as Terzaghi's extension, is widely used (Bishop, 1960). The 'effective stress' is accepted as a stress component that effectively governs the deformation, based on interpretation of the experimental effects of pore water pressure and pore air pressure on the mechanical behaviour of unsaturated soils. Therefore, as summarised in Figure 2, the stress which describes deformation of the soil skeleton of unsaturated soils is different from the partial stress on the solid phase. It is described as a form of 'effective stress', inclusive of the influences of other partial stresses. Also, from the three mass conservation laws, two independent continuity conditions are derived. Moreover, from the momentum conservation law, the 


$$
\begin{aligned}
& (\square) \text { Solid } \rightarrow \text { Gas } \rightarrow \\
& \text { Real soil Three phase Mixture model } \rho \\
& \text { Solid (soil) } \rho_{\mathrm{s}}\left(\boldsymbol{x}_{\mathrm{s}}, t\right) \text {, liquid (water) } \rho_{\mathrm{w}}\left(\boldsymbol{x}_{\mathrm{w}}, t\right) \text {, gas (air) } \rho_{\mathrm{s}}\left(\boldsymbol{x}_{\mathrm{s}}, t\right) \text {. } \\
& \text { Motion } \quad x_{\alpha}=x_{\alpha}\left(X_{\alpha^{\prime}} t\right), v_{\alpha}=\dot{x}_{\alpha^{\prime}} \alpha=\mathrm{s}, \mathrm{w}, \mathrm{a} \\
& \text { in which density: } \rho=\sum_{\alpha} \bar{\rho}_{\alpha}, \alpha=\mathrm{s}, \mathrm{w}, \mathrm{a}, \bar{\rho}_{\mathrm{s}}=(1-n) \rho_{\mathrm{s}^{\prime}} \bar{\rho}_{\mathrm{w}}=n S_{\mathrm{r}} \rho_{\mathrm{w}^{\prime}} \bar{\rho}_{\mathrm{a}}=n\left(1-S_{\mathrm{r}}\right) \rho_{\mathrm{a}} \\
& \text { Mass } \quad \dot{\bar{\rho}}_{\alpha}+\bar{\rho}_{\alpha} \operatorname{div} v_{\alpha}=0 \\
& \text { Momentum } \quad \bar{\rho}_{\alpha} \dot{v}_{\alpha}=\operatorname{div} \sigma_{\alpha}^{\top}+\bar{\rho}_{\alpha} \boldsymbol{b}_{\alpha}+\boldsymbol{\pi}_{\alpha^{\prime}}, \sigma_{\alpha}^{\top}=\sigma_{\alpha^{\prime}} \quad \sum_{\alpha} \boldsymbol{\pi}_{\alpha}=0, \boldsymbol{b}=\sum_{\alpha} \boldsymbol{b}_{\alpha} \\
& \text { Stress: total stress } \sigma=\sum_{\alpha} \sigma_{\alpha^{\prime}} \text { in which } \sigma_{\alpha} \text { : partial stress, } \alpha=\mathrm{s}, \mathrm{W}, \mathrm{a} \\
& \text { or rigorously } \sigma=\sum_{\alpha}\left(\sigma_{\alpha}-\bar{\rho}_{\alpha} \boldsymbol{u}_{\alpha} \otimes \boldsymbol{u}_{\alpha}\right), \boldsymbol{u}_{\alpha}=\dot{\boldsymbol{x}}-\rho^{-1} \sum_{\alpha} \bar{\rho}_{\alpha} \dot{\boldsymbol{x}}_{\alpha} \text { : diffusion velocity }
\end{aligned}
$$

Figure 1. Framework of the mixture theory

equation of motion for unsaturated soils as the overall mixture is derived by assuming that the relative velocities of pore water and pore air to the soil skeleton are sufficiently small (Noda and Yoshikawa, 2015; Uzuoka and Borja, 2012). The governing equations of the movement of pore water and pore air are derived as a function of a priori introduced Darcy's law by assuming the similarity of the pore fluid and pore air flow to the Hagen-Poiseuille flow through a pipe (de Boer, 1998; Nishimura, 1999).

The SWRC equation can be regarded as an expression that determines the composition ratio of each phase of the unsaturated soil, whereby the number of governing equations matches the number of unknown variables necessary to describe the mechanical behaviour of unsaturated soils. Then, the boundary value problem to describe the mechanical behaviour of unsaturated soils is summarised in Figure 3. The deformation of unsaturated soils is described by the constitutive equation into which the mechanical interactions between phases are integrated. Also, it should be noted that, following the convention of soil mechanics, infinitesimal strain is employed, and the stress and the strain are positive on the compression side.

The soil, water and air coupling formulation can be organised as shown in Figure 4, consisting of a deformation problem and two seepage problems. In this case, the SWRC is responsible for determining the degree of saturation as a mediator among these problems. Conscious of such a theoretical structure, it is easy to propose which part of the model should be improved when considering a given physical phenomenon. Furthermore, in consideration of a future computer environment for large-scale, wide-area and high-resolution computation using supercomputers and general-purpose graphics-processing units, it would become advantageous to solve the boundary value problem separately as much as possible, since an integrated system such as the Integrated Earthquake System (e.g. Hori et al., 2006) under which various kinds of simulations can be interactively handled is developed. This would facilitate the use of reliable existing simulation codes for each problem that have been well customised to be suitable to parallelised computing systems. Considering such a change in the computer environment, an attempt to solve the soil and water coupling problem by separating the deformation problem and the seepage problem was made by Takeyama et al. (2019).

\section{The constitutive model employed in the deformation problem}

In this paper, the elasto-plastic constitutive model proposed by Ohno et al. (2007) is employed in the deformation problem. This model is called the ' $S_{\mathrm{e}}$-hardening model' and is characterised by 
Effective stress and partial stress: if $\boldsymbol{\sigma}^{\prime}=\boldsymbol{\sigma}^{N}+\chi s \mathbf{1}, \boldsymbol{\sigma}^{N}=\boldsymbol{\sigma}-p_{\mathrm{a}} \mathbf{1}, s=p_{\mathrm{a}}-p_{\mathrm{w}}$ and $\boldsymbol{\sigma}=\sum \boldsymbol{\sigma}_{\alpha}$ hold

$$
\boldsymbol{\sigma}_{s}=\boldsymbol{\sigma}^{\prime}-\left\{(1-\chi)-n\left(1-S_{r}\right)\right\} p_{a} \mathbf{1}-\left(\chi-n S_{r}\right) p_{w} \mathbf{1}, \sigma_{w}=-n S_{r} p_{w} \mathbf{1}, \boldsymbol{\sigma}_{a}=-n\left(1-S_{r}\right) p_{a} \mathbf{1}
$$

1. Equilibrium equation: sum of each equation of motion (B) with neglecting acceleration

2. Effective stress: $\boldsymbol{\sigma}^{\prime}=\boldsymbol{\sigma}^{N} \chi s \mathbf{1}, \boldsymbol{\sigma}^{N}=\boldsymbol{\sigma}-p_{\mathrm{a}} \mathbf{1}, s=p_{\mathrm{a}}-p_{\mathrm{w}}(\mathrm{D})$; note that $\sigma^{\prime} \neq \sigma_{\mathrm{s}}$

3. Infinitesimal strain rate of solid: $\dot{\boldsymbol{\varepsilon}}=-\left(\operatorname{grad} \dot{\boldsymbol{x}}_{\mathrm{s}}+\operatorname{grad}^{\top} \dot{\boldsymbol{x}}_{\mathrm{s}}\right) / 2$

4. Continuity between solid and fluid: simultaneously solving the solid phase and fluid phase of (A)

5. Continuity between solid and gas: simultaneously solving the solid phase and gas phase of (A)

6. Darcy's law for fluid: interpretation of the interaction force $\pi_{\mathrm{w}}$ in the equation of motion for the fluid phase (B) based on the analogy of Hagen-Poiseuille flow under the isotropic pressure field

7. Darcy's law for gas: interpretation of the interaction force $\pi_{\mathrm{a}}$ in the equation of motion for the gas phase (B) based on the analogy of Hagen-Poiseuille flow under the isotropic pressure field

8. Constitutive equation: relation between the effective stress (not partial stress for the solid phase) and strain of the solid phase

9. Water retention model to specify the relationship between $S_{\mathrm{r}}$ and $s=p_{\mathrm{a}}-p_{\mathrm{w}}$

10. Equations of state for pore water and pore air (usually pore water is assumed to be incompressible) Note that the diffusion velocity in (C) is negligible in unsaturated soils.

$\boldsymbol{x}_{\alpha}=\mathrm{x}_{\alpha}\left(\boldsymbol{X}_{\alpha^{\prime}} t\right)$, motion of the $\alpha$ phase; $\rho_{\alpha}\left(\boldsymbol{x}_{\alpha}, t\right)$, density of the $\alpha$ phase itself; $t$, time; $\pi_{\mathrm{a}}$, internal interaction force working to the $\alpha$ phase; $\boldsymbol{b}$, body force working to the whole mixture; $\boldsymbol{b}_{\alpha^{\prime}}$, body force working to the $\alpha$ phase; $n$, porosity; $S_{r}$, degree of saturation; $\boldsymbol{\sigma}^{N}$, net stress; $\boldsymbol{\sigma}^{\prime}$, effective stress; $\boldsymbol{\sigma}$, total stress; $p_{a}$, pore air pressure; $p_{w \prime}$ pore water pressure; $s$, suction; $\chi$, Bishop's parameter (usually assumed to be $S_{\mathrm{r}}$ or the function of $S_{\mathrm{r}}$ )

Figure 2. Governing equations of unsaturated soils under quasi-static condition

the strain hardening/softening rule in the unsaturated state, formulated by a function of the effective degree of saturation, $S_{\mathrm{e}}=\left(S_{\mathrm{r}}-S_{\mathrm{r} 0}\right) /\left(1-S_{\mathrm{r} 0}\right)$. In this, $S_{\mathrm{r}}$ is the degree of saturation and the subscript 0 denotes the value at the driest state, where only meniscus water around the soil particle remains.

The yield function is described as

$$
\begin{aligned}
& f\left(\boldsymbol{\sigma}^{\prime}, S_{\mathrm{e}}, \varepsilon_{\mathrm{v}}^{\mathrm{p}}\right)=\frac{\lambda-\kappa}{1+e_{0}} \ln \frac{p^{\prime}}{\xi p_{\mathrm{sat}}^{\prime}} \\
& +\frac{\lambda-\kappa}{\left(1+e_{0}\right) n_{\mathrm{E}}}\left(\frac{\eta^{*}}{M}\right)^{n_{\mathrm{E}}}-\varepsilon_{\mathrm{v}}^{\mathrm{p}}=0
\end{aligned}
$$

in which $\lambda$ is the compression index; $\kappa$ is the swelling index; $M$ is the critical state parameter introduced in the Cam-Clay model; $p^{\prime}$ is the effective mean stress; $p_{\text {sat }}^{\prime}$ is the effective mean stress at the pre-consolidation state under the fully saturated condition; $e$ is the void ratio; $e_{0}$ is the void ratio at the reference; $\varepsilon_{\mathrm{v}}^{\mathrm{p}}$ is the plastic component of volumetric strain; $\eta^{*}$ is the generalised deviator stress ratio originally introduced by Sekiguchi and Ohta (1977) to describe the dilatancy behaviour due to deviator stresses; and $n_{\mathrm{E}}$ is a parameter to adjust the rate of dilatancy development, as described by Ohno et al. (2007, 2013). In this model, the yielding effective mean stress $p_{\mathrm{c}}^{\prime}$ at the unsaturated state is assumed as

2. $p_{\mathrm{c}}^{\prime}=\xi p_{\mathrm{sat}}^{\prime}$

and

3. $\xi=\exp \left[\left(1-S_{\mathrm{e}}\right)^{n_{\mathrm{s}}} \ln a\right]$

in which the parameter $\xi$ determines the degree of the effect of unsaturation on the pre-consolidation stress and $a$ and $n_{\mathrm{s}}$ are fitting parameters to adjust it. 


\section{Governing equations}

1. Equation of motion $\rho \dot{\boldsymbol{v}}=\operatorname{div} \boldsymbol{\sigma}^{\top}+\rho \boldsymbol{g}, \boldsymbol{\sigma}^{\top}=\boldsymbol{\sigma}$

2. Effective stress $\boldsymbol{\sigma}^{\prime}=\boldsymbol{\sigma}^{\mathrm{N}}+\chi\left(S_{\mathrm{r}}\right) s \mathbf{1}$,

$$
\boldsymbol{\sigma}^{N}=\boldsymbol{\sigma}-p_{\mathrm{a}} \mathbf{1}, \mathbf{s}=p_{\mathrm{a}}-p_{\mathrm{w}}
$$

3. Infinitesimal strain $\dot{\boldsymbol{\varepsilon}}=-\left(\operatorname{grad} \dot{\boldsymbol{u}}+\operatorname{grad}^{\top} \dot{\boldsymbol{u}}\right) / 2$

4. Continuity equation (solid and liquid phases)

$$
S_{r} \dot{\varepsilon}_{v}-\boldsymbol{n} \dot{S}_{\mathrm{r}}-\operatorname{div} \tilde{\boldsymbol{v}}_{\mathrm{w}}=0
$$

5. Continuity equation (solid and gas phases)

$$
\left(1-S_{r}\right) \dot{\varepsilon}_{v}+\boldsymbol{n} \dot{S}_{r}-\boldsymbol{n}\left(1-S_{r}\right) \frac{\dot{\rho}_{a}}{K_{a}}-\operatorname{div} \tilde{v}_{a}=0
$$

6. Darcy's law for liquid phase $\tilde{\boldsymbol{v}}_{\mathrm{w}}=-k_{\mathrm{w}} \mathrm{grad} h_{\mathrm{w}}$

7. Darcy's law for gas phase $\tilde{\boldsymbol{v}}_{\mathrm{a}}=-k_{\mathrm{a}} \operatorname{grad} h_{\mathrm{a}}$

8. Constitutive equation of soil structure

$$
\boldsymbol{\sigma}^{\prime}=\boldsymbol{C e p} \dot{\boldsymbol{\varepsilon}}-\boldsymbol{\sigma}^{S_{\mathrm{r}}}\left(S_{\mathrm{r}}\right)
$$

9. SWRCs $S_{r}=S_{r}(s)$

10. Compressibility of gas phase $\dot{p}_{\mathrm{a}}=K_{\mathrm{a}} \frac{\dot{\rho}_{\mathrm{a}}}{\rho_{\mathrm{a}}}$

\section{Boundary conditions}

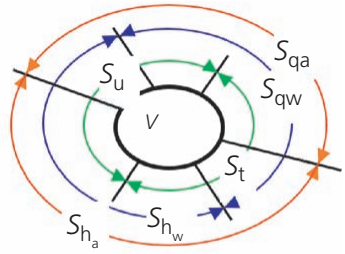

Dirichlet

Displacement: $\boldsymbol{u}$ on $\boldsymbol{S}_{\mathrm{u}}$ Water head: $h_{w}$ on $S_{h_{w}}$ Air head: $h_{\mathrm{a}}$ on $S_{h_{a}}$

Neumann

Traction: $\boldsymbol{t}=\boldsymbol{\sigma}^{\top} \boldsymbol{n}$ on $S_{t}$ Water flux: $q_{w}=\tilde{\boldsymbol{v}}_{\mathrm{w}} \cdot \boldsymbol{n}$ on $S_{q_{\mathrm{w}}}$ Air flux: $q_{\mathrm{a}}=\tilde{\boldsymbol{v}}_{\mathrm{a}} \cdot \boldsymbol{n}$ on $S_{q_{\mathrm{a}}}$ $S=S_{t}+S_{u}=S_{q_{w}}+S_{h_{w}}=S_{q_{a}}+S_{h_{a}}$

Figure 3. A concrete description of the soil-water-air coupling problem

$$
\begin{aligned}
& \begin{array}{l}
\text { Dynamic/deformaion } \\
\text { problem }
\end{array}\left\{\begin{array}{l}
\rho \dot{\boldsymbol{v}}=\operatorname{div} \boldsymbol{\sigma}^{\top}+\rho \boldsymbol{g}, \boldsymbol{\sigma}=\boldsymbol{\sigma}^{\top} \\
\boldsymbol{\varepsilon}=-\frac{1}{2}\left(\frac{\partial \boldsymbol{u}}{\partial \mathbf{x}}+\left(\frac{\partial \boldsymbol{u}}{\partial \mathbf{x}}\right)^{\top}\right) \\
\boldsymbol{\sigma}=\boldsymbol{C}^{\mathrm{ep}} \boldsymbol{\varepsilon}-\boldsymbol{\sigma}^{S_{\mathrm{r}}}\left(S_{\mathrm{r}}\right)+p_{\mathrm{a}} \mathbf{1}-\chi\left(S_{\mathrm{r}}\right)\left(p_{\mathrm{a}}-p_{\mathrm{w}}\right) \mathbf{1}
\end{array}\right. \\
& p_{\mathrm{w}} \text { or } h_{\mathrm{w}} \\
& \text { SWRC } \\
& S_{r}=S_{r}\left(p_{a}-p_{w}\right) \\
& p_{\mathrm{a}} \text { or } h_{\mathrm{a}} \\
& \left(1-S_{\mathrm{r}}\right) \dot{\varepsilon}_{\mathrm{v}}+n \dot{S}_{\mathrm{r}}-n\left(1-S_{\mathrm{r}}\right) \frac{\dot{p}_{\mathrm{a}}}{K_{\mathrm{a}}} \\
& =-k_{\mathrm{a}} \operatorname{div}\left(\operatorname{grad} h_{\mathrm{a}}\right)
\end{aligned}
$$

Figure 4. Theoretical structure of the soil-water-air coupling problem

In the stress and strain expression, the effective stress can be described using the elastic component of strain as

4. $\dot{\boldsymbol{\sigma}}^{\prime}=\boldsymbol{C}^{\mathrm{e}}: \dot{\boldsymbol{\varepsilon}}^{\mathrm{e}}+K_{S_{\mathrm{e}}} \dot{S}_{\mathrm{e}} \boldsymbol{1}$

and

5. $K=\frac{1+e_{0}}{\kappa} p^{\prime}$

6. $K_{S_{\mathrm{e}}}=-n_{\mathrm{s}} p^{\prime} \ln a\left(1-S_{\mathrm{e}}\right)^{n_{\mathrm{s}}-1}$

\section{7. $\boldsymbol{C}^{\mathrm{e}}=K \mathbf{1} \otimes \mathbf{1}+2 G \boldsymbol{A}$}

8. $G=\frac{3\left(1-2 v^{\prime}\right)}{2\left(1+v^{\prime}\right)} K$

in which $K$ is the bulk modulus; $K_{S_{\mathrm{e}}}$ is the bulk modulus at the unsaturated state; $G$ is the shear modulus; $v^{\prime}$ is Poisson's ratio in terms of the effective stress; $\boldsymbol{C}^{\mathrm{e}}$ is the elastic stiffness tensor; $\boldsymbol{1}$ is the second-order identity tensor; $\boldsymbol{A}$ is the fourth-order deviatoric tensor defined by $\boldsymbol{A}=\boldsymbol{I}-(1 / 3)(\boldsymbol{1} \otimes \mathbf{1})$; and $\boldsymbol{I}$ is the fourth-order identity tensors. The stress-strain relation is derived based on the associated flow rule as 


$$
\begin{aligned}
& \dot{\boldsymbol{\sigma}}^{\prime}=\left[\boldsymbol{C}^{\mathrm{e}}-\frac{\boldsymbol{C}^{\mathrm{e}}: \frac{\partial f}{\partial \boldsymbol{\sigma}^{\prime}} \otimes \frac{\partial f}{\partial \boldsymbol{\sigma}^{\prime}}: \boldsymbol{C}^{\mathrm{e}}}{\frac{\partial f}{\partial \boldsymbol{\sigma}^{\prime}}: \boldsymbol{C}^{\mathrm{e}}: \frac{\partial f}{\partial \boldsymbol{\sigma}^{\prime}}+\frac{\partial f}{\partial p^{\prime}}}\right] \\
& : \dot{\boldsymbol{\varepsilon}}-\left[\frac{\boldsymbol{C}^{\mathrm{e}}: \frac{\partial f}{\partial \boldsymbol{\sigma}^{\prime}}\left(\frac{\partial f}{\partial p^{\prime}} K_{S_{\mathrm{e}}}+\frac{\partial f}{\partial S_{\mathrm{e}}}\right)}{\frac{\partial f}{\partial \boldsymbol{\sigma}^{\prime}}: \boldsymbol{C}^{\mathrm{e}}: \frac{\partial \mathrm{f}}{\partial \boldsymbol{\sigma}^{\prime}}+\frac{\partial f}{\partial p^{\prime}}}-K_{S_{\mathrm{e}}} \mathbf{1}\right] \dot{S}_{\mathrm{e}} \Leftrightarrow \dot{\boldsymbol{\sigma}}^{\prime} \\
& \text { 9. }=\boldsymbol{C}^{\mathrm{ep}}: \dot{\boldsymbol{\varepsilon}}-\boldsymbol{\sigma}^{S_{\mathrm{r}}}\left(S_{\mathrm{e}}\right) \dot{S}_{\mathrm{e}}
\end{aligned}
$$

Thus, a concrete description of the constitutive equation of the soil skeleton is provided, where the second-order stress term tensor arising from the change of the degree of saturation in Figure 3, $\boldsymbol{\sigma}^{S_{\mathrm{r}}}\left(S_{\mathrm{r}}\right)$, is expressed as the function of the effective degree of saturation as $\boldsymbol{\sigma}^{S_{\mathrm{r}}}\left(S_{\mathrm{e}}\right)$.

This model can seamlessly describe the mechanical behaviour of soils from the unsaturated to the fully saturated state. In the fully saturated state, it is automatically reduced to the type of Cam-Clay model for saturated soils. In this sense, it is an extension of the Cam-Clay model for the unsaturated state. A comparison between experimental data and computed results by this model is shown in Figures 5(a) and 5(b). The experiment for unsaturated soils was performed using the triaxial apparatus by Kato (1998), in which suction and confining stress are applied to a compacted specimen, as shown in Figure 5(c).

This constitutive model can be easily extended to a dynamic problem under seismic loading conditions by introducing the subloading surface and rotational hardening concepts proposed by Hashiguchi (1980, 1989). The extended yield function is described as

$$
f=M D \ln \frac{\bar{p}^{\prime}}{p_{0}^{\prime}}+\frac{M \bar{D}}{n_{\mathrm{E}}}\left(\frac{\bar{\eta}^{*}}{M}\right)^{n_{\mathrm{E}}}-\varepsilon_{\mathrm{v}}^{\mathrm{p}}-M \bar{D} \ln R=0
$$

in which $\bar{D}$ is the dilatancy coefficient proposed by Shibata (1963) and has the relation with $M$ as $\bar{D}=(\lambda-\kappa) /\left[M\left(1+e_{0}\right)\right]$. The modified effective stress is defined as $\overline{\boldsymbol{\sigma}}^{\prime}=\boldsymbol{\sigma}^{\prime}-(1-R) \boldsymbol{\alpha}$, in which $\alpha$ is the similarity centre of the subloading surface. In the case that the similarity centre is set to be the origin, $\alpha=0$ is held. The modified mean effective stress and the modified generalised stress ratio are defined as

11. $\bar{p}^{\prime}=\operatorname{tr}\left(\overline{\boldsymbol{\sigma}}^{\prime}\right) / 3$

12. $\bar{\eta}^{*}=\sqrt{\frac{3}{2}}\left\|\overline{\boldsymbol{\eta}}-\boldsymbol{\eta}_{\mathrm{e}}\right\|$ in which $\overline{\boldsymbol{\eta}}$ is the modified stress ratio tensor determined by dividing the modified stress deviator $\overline{\boldsymbol{s}}$ by $\bar{p}^{\prime}$. The evaluation law of $\boldsymbol{\alpha}$ and $\boldsymbol{\eta}_{\mathrm{e}}$ are given as

$$
\dot{\boldsymbol{\alpha}}=c_{\alpha}\left\|\dot{\boldsymbol{\varepsilon}}^{\mathrm{p}}\right\|\left(\boldsymbol{\sigma}^{\prime}-\boldsymbol{\alpha}\right)+\frac{1}{p_{\mathrm{c}}^{\prime}}\left\{\dot{p}_{\mathrm{c}}^{\prime}-\dot{\boldsymbol{\eta}}_{\mathrm{e}} \frac{\partial f\left(p_{\alpha}^{\prime}, \eta_{\alpha}^{*}\right)}{\partial \boldsymbol{\eta}_{\mathrm{e}}}\right\} \boldsymbol{\alpha}
$$

$$
\dot{\boldsymbol{\eta}}_{\mathrm{e}}=b_{\mathrm{r}}\left\{m_{\mathrm{r}}\left(\boldsymbol{\eta}-\boldsymbol{\eta}_{\mathrm{e}}\right)-\left\|\boldsymbol{\eta}-\boldsymbol{\eta}_{\mathrm{e}}\right\| \boldsymbol{\eta}_{\mathrm{e}}\right\}\left\|\dot{\boldsymbol{\varepsilon}}_{\mathrm{d}}^{\mathrm{p}}\right\|
$$

in which $\boldsymbol{\varepsilon}_{\mathrm{d}}^{\mathrm{p}}$ is the plastic component of deviator strain; $c_{\alpha}$ is the parameter which controls the moving rate of the similarity centre; $b_{\mathrm{r}}$ is the parameter which controls the rotational rate of the yield surface; and $m_{\mathrm{r}}$ is the parameter which defines the rotational limit of the yield surface.

Castro (1969), Tatsuoka (1972) and others reported that the hardening of a sandy soil is caused not only by plastic volumetric change, but also by plastic shear distortion. Hashiguchi and Chen (1998) proposed the hardening/softening law due to shearing. The evaluation law of the hardening parameter $H$ is given as

15. $\dot{H}=\dot{\varepsilon}_{\mathrm{v}}^{\mathrm{p}}+\sqrt{\frac{2}{3}} \mu\left\|\dot{\boldsymbol{\varepsilon}}_{\mathrm{d}}^{\mathrm{p}}\right\|_{\left(\eta-M_{\mathrm{d}}\right)}$

in which $\mu$ is the parameter which controls the contribution of the hardening/softening due to shear. $M_{\mathrm{d}}$ is the parameter which defines the boundary between the hardening and softening.

In mathematical modelling to solve the boundary value problem, the SWRC model proposed by Kawai et al. (2007a) is also employed. In this model, the drying and the wetting processes in the SWRC are separately formulated using logistic curves in the space of the degree of saturation and suction to describe the hysteresis loops with suction change. The permeability of pore water in the unsaturated state is modelled to decrease with desaturation after the paper by Mualem (1976).

\section{Application case 1: differential settlement due to planting}

Wojtasik and Jez (2000) reported that absorption by trees caused differential settlement of the ground surface and the development of cracks in an adjacent concrete apartment building. Figure 6 shows the development of cracks in an adjacent concrete building next to a grouping of trees. Cracks gradually appeared in the building, which was built in 1961. After the trees were cut down in 1993, crack progression halted. According to the report, the soil foundation originally had a high moisture content, but the water content was diminished when a soil investigation was carried out in 1986, as shown in Figure 6. It was concluded that absorption by trees had caused a decrease in the water content of the foundation, resulting in differential settlement of the ground. 


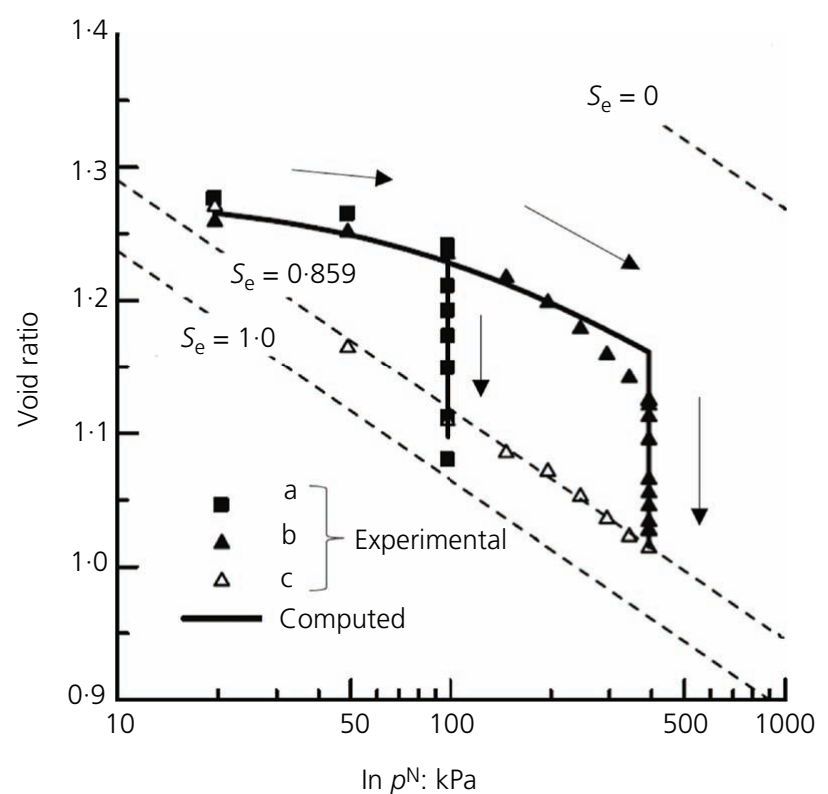

(a)

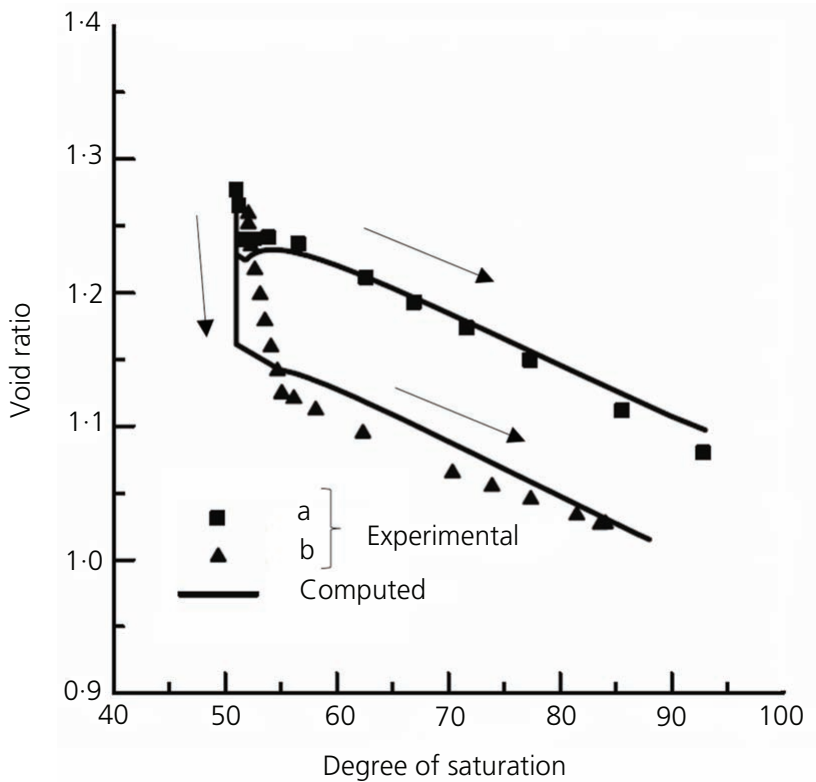

(b)

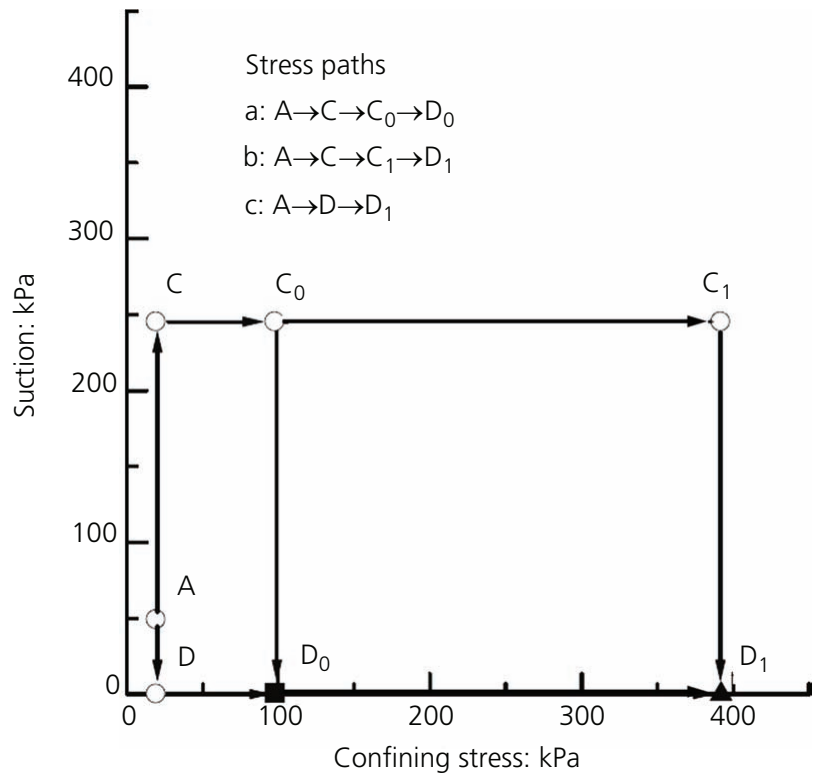

(c)

Figure 5. Performance of model - comparison between computed and experimental results

A numerical simulation was carried out to realise quantitatively the effect of plants on differential settlement (Kawai et al., 2008). Figure 7 represents the finite-element mesh used in the computation. The foundation soil consists of contractile Poznan clay, and its surface is covered by sandy boulder clay. The planted trees are aspens, willows and maple, and the apartment building was constructed $10 \mathrm{~m}$ away from the trees. To investigate the effects of these trees, numerical simulation modelled the annual underground root growth by extending the finite-element region, as shown in Figure 7, in which the growth of root system of trees under the ground is expressed by contour. In this, the pore water in the root area is drained to correspond to the amount of transpiration from trees, estimated from climate conditions at the site by the Penman model (Penman, 1948). The groundwater table was reported to be $10 \mathrm{~m}$ below the ground surface, and the foundation soil above the water table is treated as in the unsaturated state. The assumed SWRC curve is shown in Figure 8. The average amount of annual precipitation at the site and the annual evaporation, also estimated by Penman model, are imposed on the ground surface as hydraulic boundary conditions. The estimated values from 1960 to 2000 are shown in Figure 9. The initial suction distribution in the unsaturated region above the groundwater table is assumed to be as shown in 
Extension of unsaturated soil mechanics

and its applications

lizuka, Tachibana, Takeyama et al.
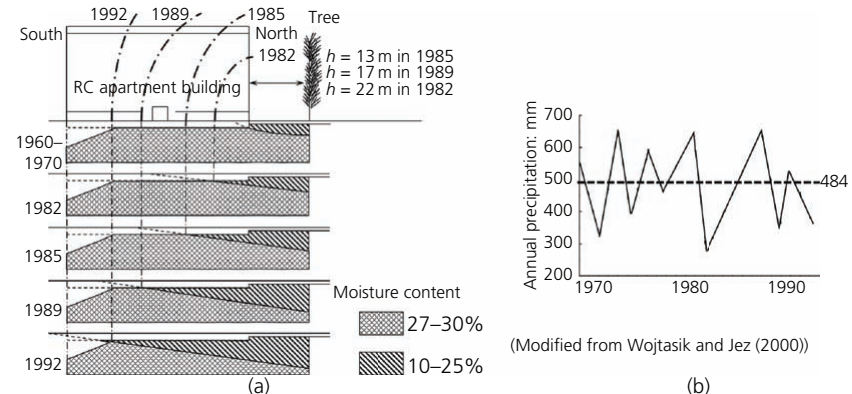

(Modified from Wojtasik and Jez (2000)

Figure 6. Differential settlement caused by plants. RC, reinforced concrete

Figure 10. Here, since the distribution of the degree of saturation above the groundwater table can be estimated from the distribution of water content (see Figure 6) under the assumption that the void ratio is constant, the initial suction distribution can be estimated from the SWRC (the average value of wetting and drying curves in Figure 8 was used). For reference, the influence of initial and boundary conditions in the unsaturated ground on its mechanical behaviour is numerically examined by Tanaka et al. (2010a, 2010b).

Three cases are compared: the case where precipitation, transpiration through vegetation and evaporation from the ground surface are

considered (case A); the case where precipitation and evaporation are considered, but transpiration is not taken into account (case B); and the case where precipitation, transpiration and evaporation are not considered at all (case C). Figure 11 shows the computed surface settlement and change in the degree of saturation with time at the right corner of the building. In case $\mathrm{A}$, the degree of saturation decreases with year, which is consistent with the occurrence of the

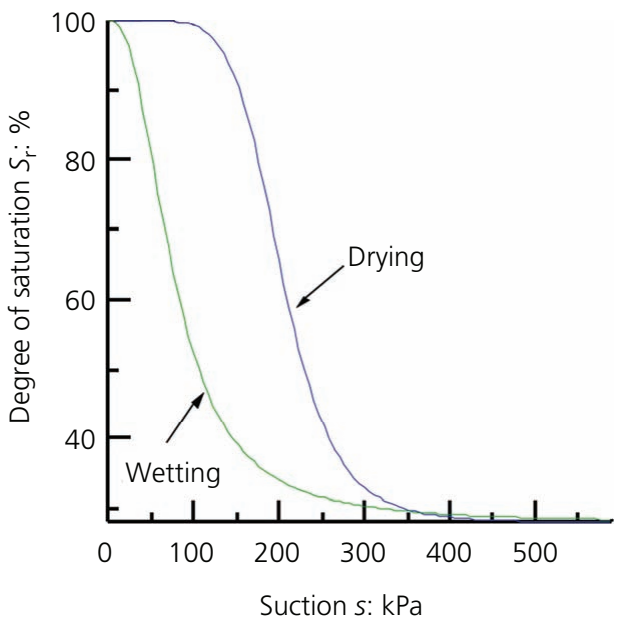

Figure 8. SWRC curve used in computation

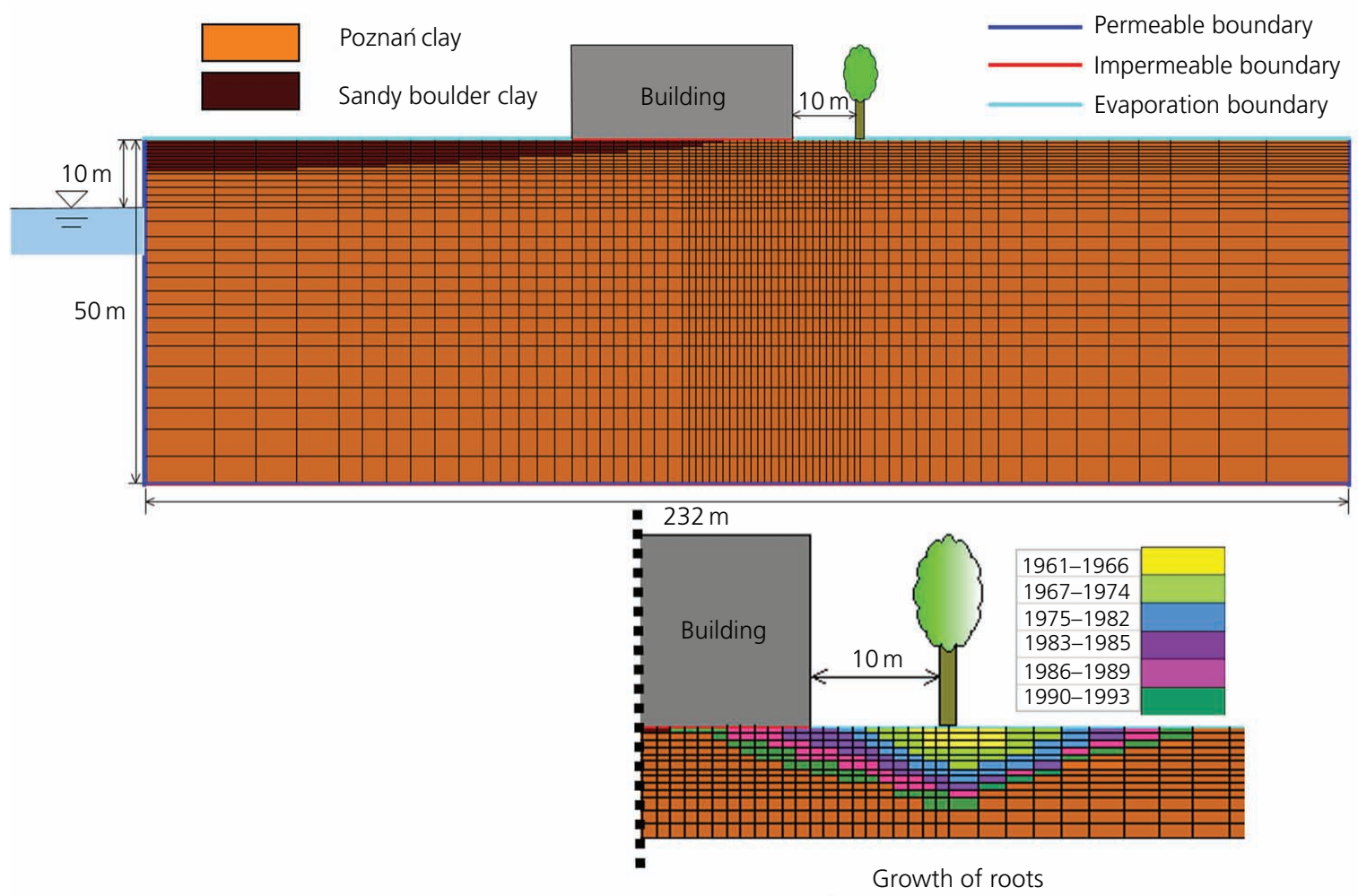

Figure 7. Finite-element modelling and growth of roots 


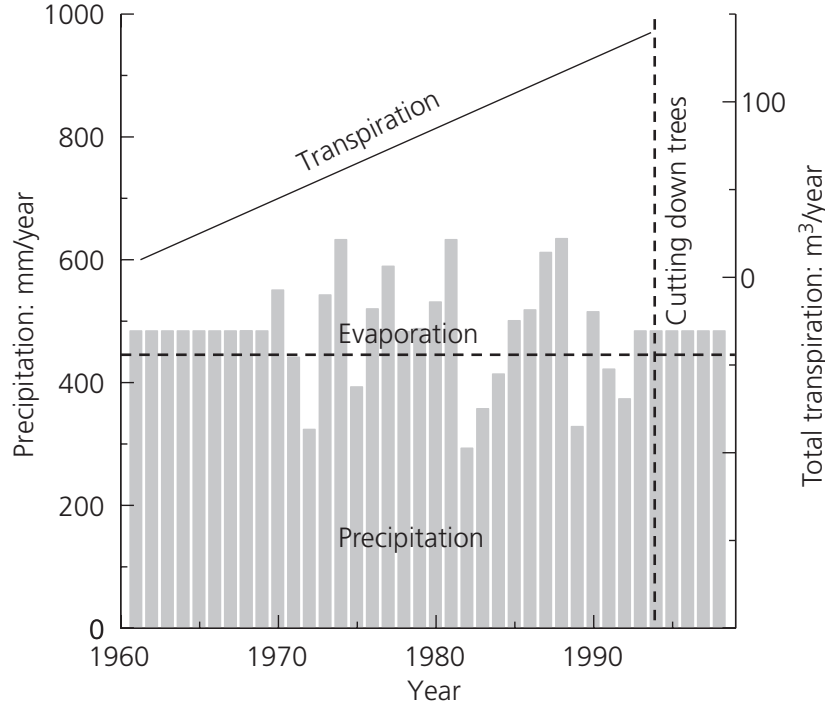

Figure 9. Hydraulic boundary conditions

settlement. The degree of saturation was found to drop suddenly in 1983, likely because tree roots reached under the building around 1983. Figure 12 indicates the surface settlement profile under the building in 1998. These findings showed that trees greatly influenced the occurrence of differential settlement, as seen in comparison to the initial settlement due to the self-weight of the building. There is no record of monitoring the settlement in this site to compare with the computed results, but at least it can be said that computed result considering the influence due to growth of trees (case A) well

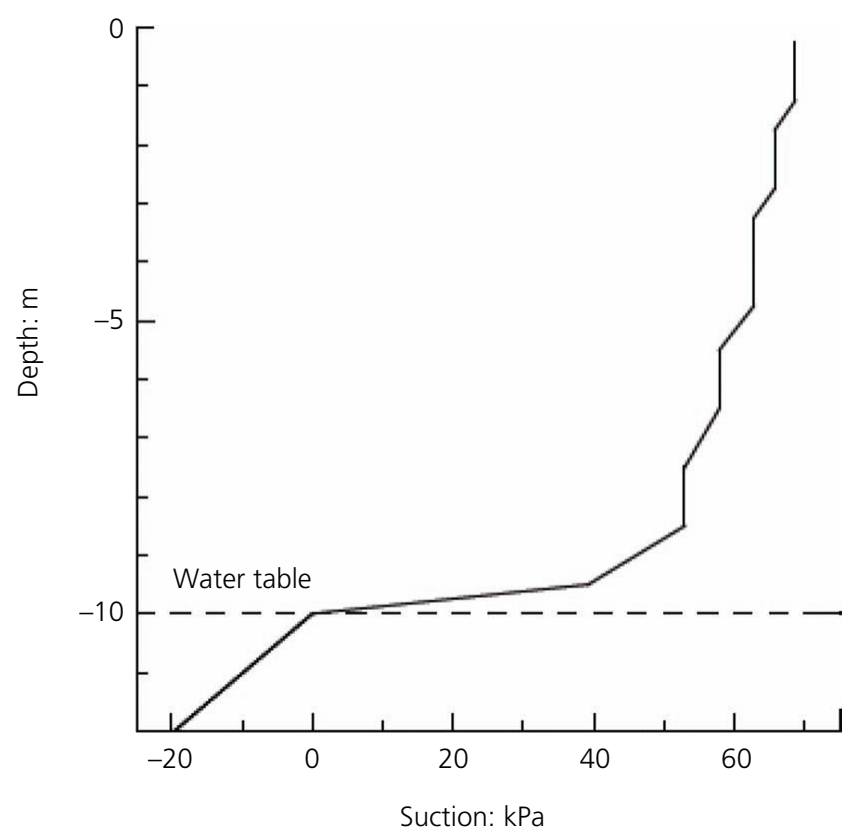

Figure 10. Assumed initial suction distribution explains the development of differential settlement and is consistent with the occurrence of cracks in the apartment building, which was observed in the site.

For reference, the differential settlement of an unsaturated compacted soil due to rainfall is also discussed by Kawai et al. (2007a) based on the unsaturated soil mechanics and the influence of water absorption by vegetation on the deformation of an unsaturated ground was investigated Kawai et al. (2007b).

\section{Application case 2: consideration of the dissolution, advection and diffusion of a substance in pore water}

In this section, a trial to apply unsaturated soil mechanics to the salt damage problem is presented. In the salt damage problem, it is necessary to consider dissolution of salt in groundwater and its advection/diffusion. The mathematical modelling of transfer of water-soluble material in the deformable saturated/unsaturated ground is discussed by Nomura et al. (2011). In this section, its theoretical framework is reviewed and its application to the salt damage problem is presented.

To apply unsaturated soil mechanics to the salt damage problem, the following are assumed.

- There is no volume change of pore water due to dissolution of salt.

- Diffusion of dissolved salt follows Fick's law.

- The permeability coefficient does not change, even with dissolution of salt.

- The salinity does not affect the mechanical constitutive relationship.

The mass change due to dissolution of salt is explained in Figure 13. When $\gamma$ is defined as the mass of the dissolved solute in the saturated dissolution per unit mass and $c$ is the concentration defined as the mass of the dissolved solute normalised by the mass of the dissolved solute in the saturated dissolution, the ratio of the mass of the dissolved solute $\left(M_{\mathrm{c}}\right)$ and the solution pore water $\left(M_{\mathrm{f}}\right)$ to the solvent $\left(M_{\mathrm{w}}\right)$ is expressed as $M_{\mathrm{w}}: M_{\mathrm{c}}: M_{\mathrm{f}}=1: \gamma_{c}:(1+\gamma \mathrm{c})$. Therefore, the continuity equation considering the dissolution of the salt is derived from the mass conservation law as

$$
-\dot{\varepsilon}_{\mathrm{v}} S_{\mathrm{r}}+n \dot{S}_{\mathrm{r}}+\frac{\gamma}{1+\gamma c} n S_{\mathrm{r}} \dot{c}+\operatorname{div} \widetilde{v}_{\mathrm{w}}=0
$$

16.

$$
\text { and } \widetilde{\boldsymbol{v}}_{\mathrm{w}}=-k_{\mathrm{w}} \operatorname{grad} h_{\mathrm{w}}
$$

The seepage equation in Figure 4 is replaced by Equation 16 . Likewise, a diffusion/advection equation is derived as

$$
-\dot{\varepsilon}_{\mathrm{v}} S_{\mathrm{r}} c+n \dot{S}_{\mathrm{r}} c+n S_{\mathrm{r}} \dot{c}+\operatorname{div}\left(c \widetilde{\boldsymbol{v}}_{\mathrm{w}}\right)+n S_{\mathrm{r}} \operatorname{div} \boldsymbol{J}=0
$$

17.

$$
\text { and } \boldsymbol{J}=-D \operatorname{grad} c
$$




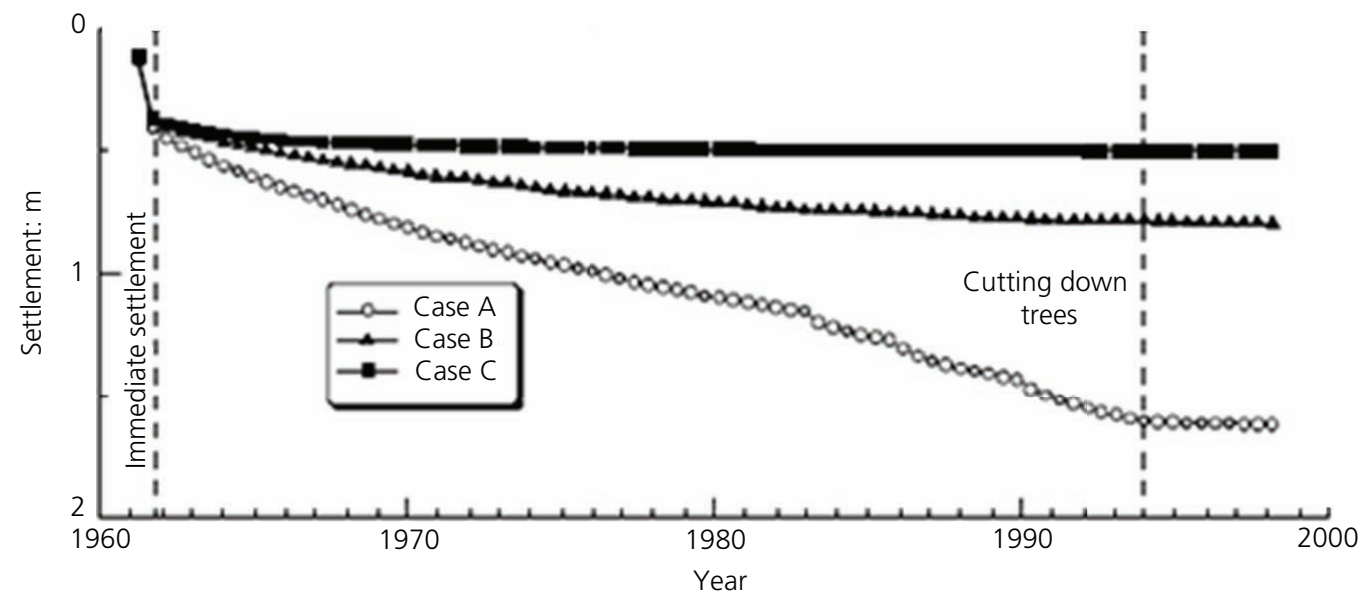

(a)

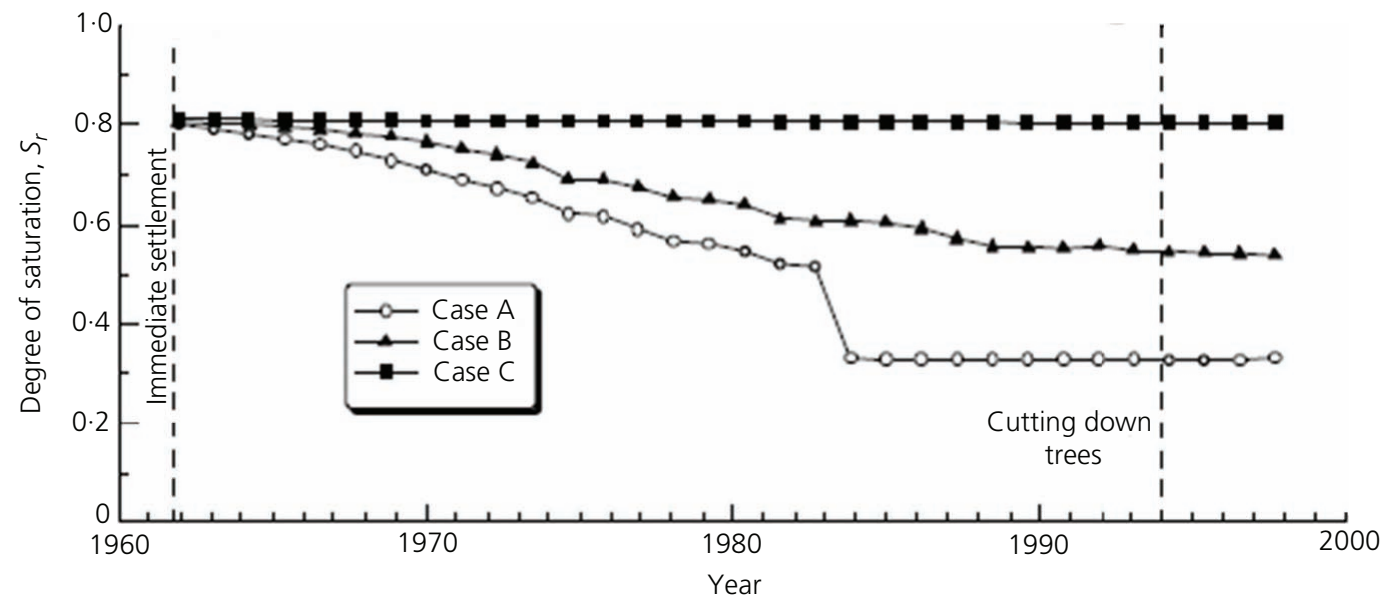

(b)

Figure 11. Computed surface settlement and change in the degree of saturation over time at the right corner of the building: (a) computed surface settlement; (b) computed degree of saturation

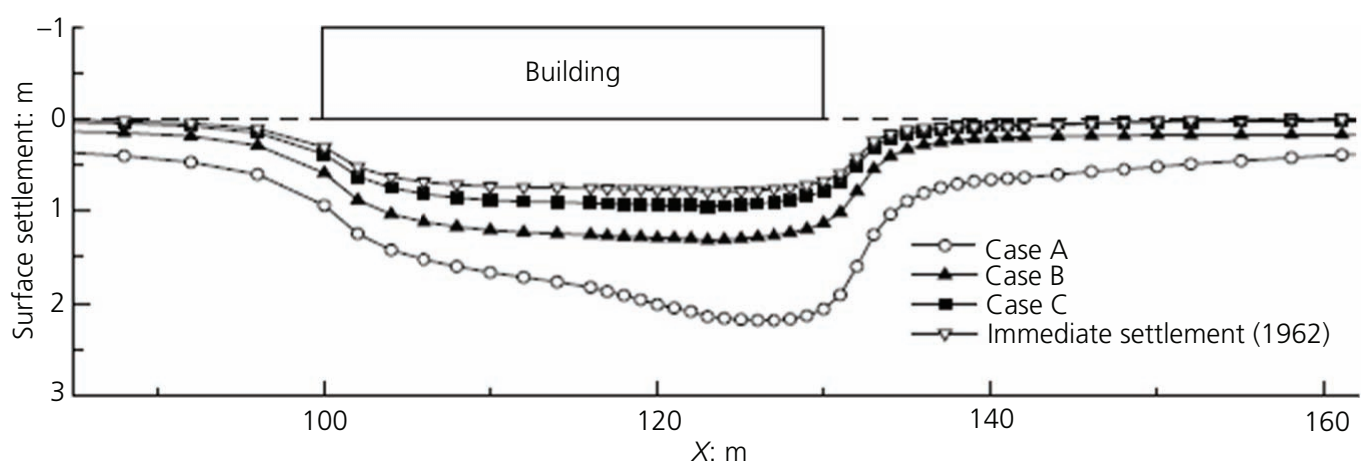

Figure 12. Surface settlement profile under the building in the year 1998

Both the diffusion/advection equation and the boundary conditions

$$
\bar{c}=c \quad \text { on } S_{\mathrm{c}}
$$

18. $\bar{Q}=\left(c \widetilde{\boldsymbol{v}}_{\mathrm{w}}\right) \cdot \boldsymbol{n}+\boldsymbol{J} \cdot \boldsymbol{n}$ on $S_{\mathrm{Q}}$ are added to the governing equations, in which $S_{\mathrm{r}}$ is the degree of saturation; $n$ is the porosity; $\widetilde{\boldsymbol{v}}_{\mathrm{w}}$ is the relative velocity of pore water; $\boldsymbol{J}$ is the concentration flux; $D$ is the diffusion coefficient; $\bar{c}$ is the known value of salt concentration on the boundary; $\boldsymbol{n}$ is the unit normal vector on the boundary surface, $S_{\mathrm{Q}} ; S_{\mathrm{c}}$ 
Volume

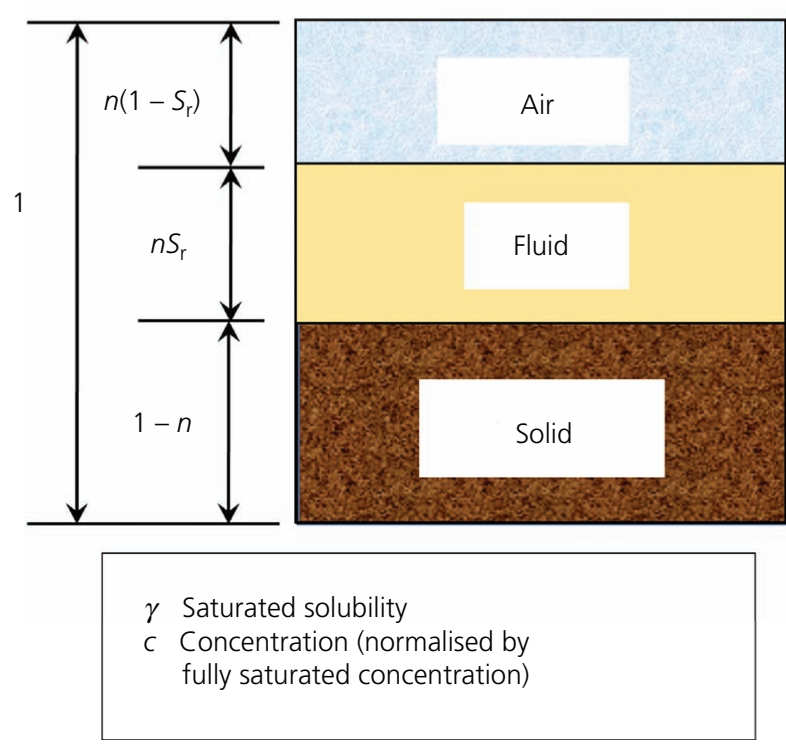

$M_{c}: g / l \mathrm{~g} \mathrm{H}_{2} \mathrm{O}$
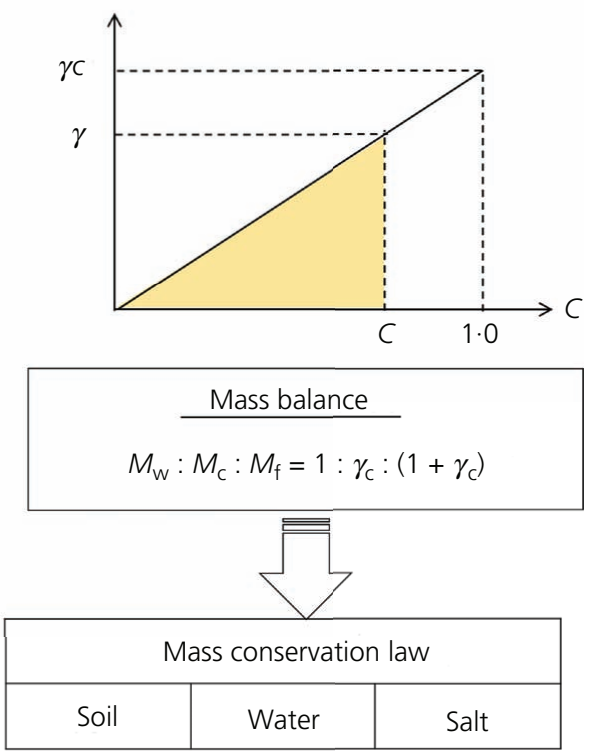

Figure 13. Treatment of dissolved materials (salt)

and $\bar{Q}$ are known values of the total flux on the boundary surface, $S_{\mathrm{Q}}$.

An application case of this problem follows. The unsaturated soil shown in Figure 14 is considered, in which the groundwater is saline with a concentration of $0.03(3 \%)$, and its water level is located $4.0 \mathrm{~m}$ below the ground surface. When evaporation and rainfall repeatedly act on the ground surface, the transfer of salinity to the unsaturated soil above the groundwater level is computed. Herein, based on the climate data in the north-eastern part of Thailand, the monthly average evapotranspiration from the ground surface estimated from the Penman model (Penman, 1948) and the monthly average rainfall (Figure 15) are repeatedly input on the ground surface for 8 years as boundary conditions. The ground employed in the computation is assumed to be a soft clayey unsaturated soil, in which the compression index $\lambda=0 \cdot 06$, the swelling index $\kappa=0 \cdot 01$, the critical state parameter $M=1 \cdot 33$, the Poisson's ratio $v^{\prime}=0 \cdot 30$, the permeability coefficient $k_{\mathrm{w}}=1 \cdot 0 \times$ $10^{-4} \mathrm{~cm} / \mathrm{s}$ and the Mualem's constant (Mualem, 1976) $m=0 \cdot 30$. The SWRC of the ground is assumed as shown in Figure 16. The computation results are presented in Figure 17. Salinity concentrations rise towards the ground surface year by year (Figure 17(a)). The monthly total water head distributions in the ground are shown in Figure 17(b). An upward hydraulic gradient appears in the dry season, and in the opposite direction, a downward hydraulic gradient develops in the rainy season. Throughout a year, the upward hydraulic gradient seems dominant to the downward hydraulic gradient, resulting in salt deposition on the ground surface within 3 years, as shown in Figure 17(c). Here, the value on the vertical axis in Figure 17(c) indicates the ratio of the solute (salt in this case) exceeding the saturated dissolution amount against the dissolved solute in the saturated dissolution.

To inhibit such salt damage, a mulching technique is examined where gravel is placed on the ground surface, presenting a capillary barrier. Assuming the mulch layer's permeability coefficient is eight times higher and its SWRCs poorer than those of the ground surface, as shown in Figure 18, Figure 19 presents the effects of mulching using different layering conditions. In this, rainfall and evaporation inputs to the ground surface are the same as in Figure 15.

For reference, the solute transfer during consolidation of the ground based on the solid-fluid-solute coupling model is discussed by Nomura et al. (2018).

\section{Application case 3: consideration of pore air solution}

The physical phenomenon in which dissolved air in pore water vaporises is described by Henry's law. This section considers incorporating this phenomenon into the soil, water and air coupling problem. However, in order to simplify the problem, the following are assumed.

- Dissolved gas has no volume in the liquid phase and does not change the volume of the liquid phase, even if it dissolves.

- Temperature change accompanied by dissolution is not considered. 
Geotechnical Research

Volume 6 Issue GR3
Extension of unsaturated soil mechanics

and its applications

lizuka, Tachibana, Takeyama et al.

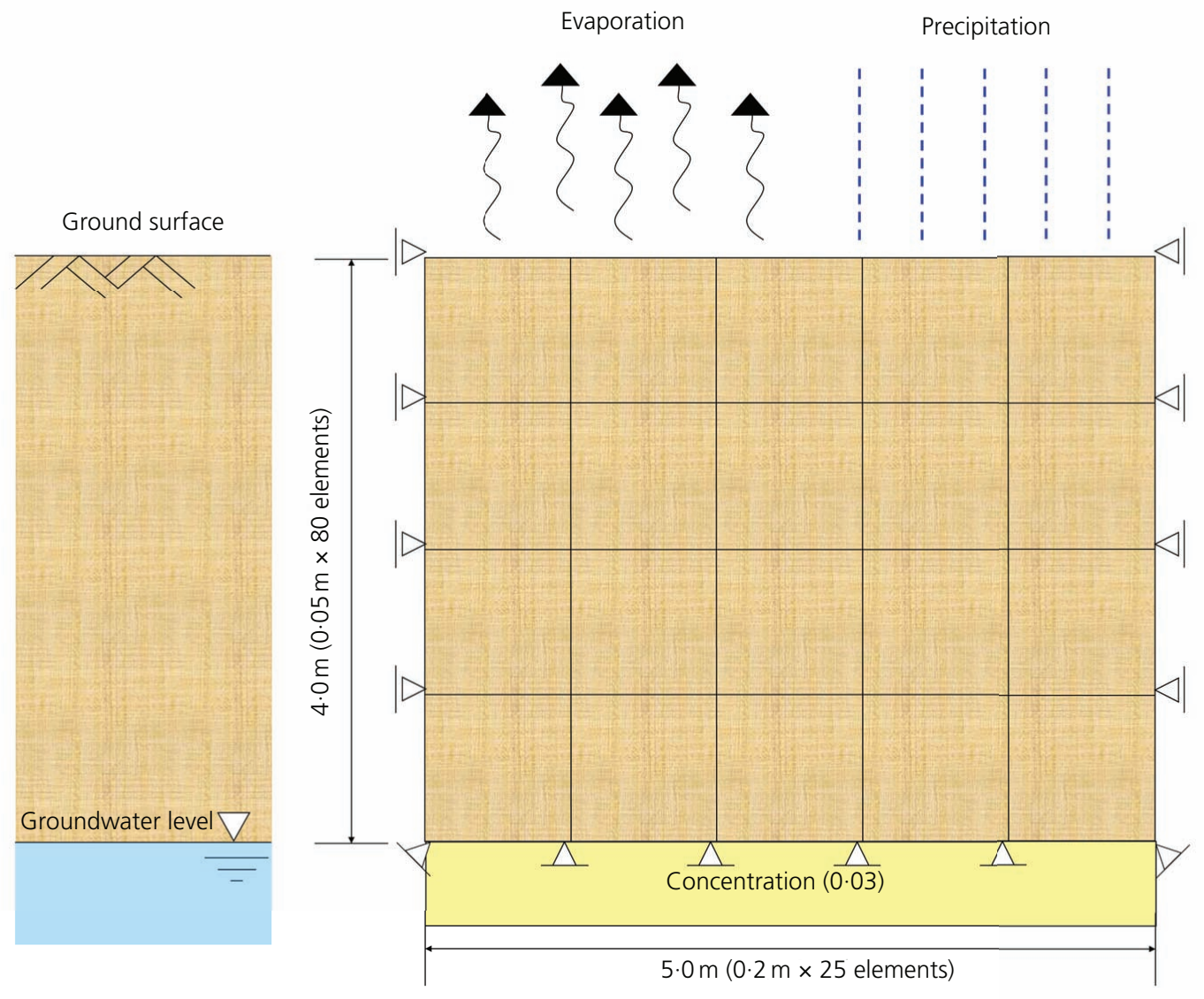

Figure 14. Model ground

- The dissolution rate of the gas is extremely quick, and the pore water reaches a saturated state immediately, with the amount of dissolved gas proportional to pressure (Shuurman, 1996).

$250-$

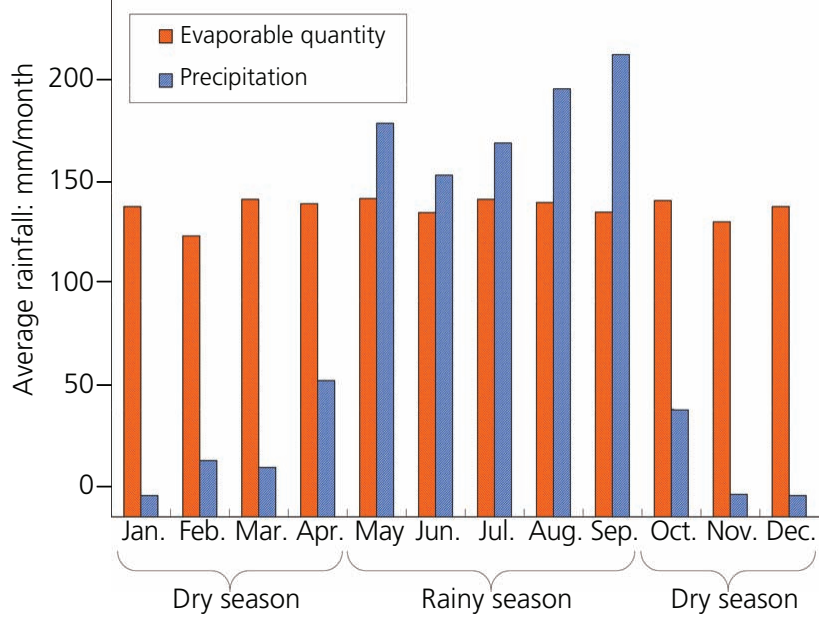

Figure 15. Climate conditions for simulation
- The state change of pore water itself is not considered.

Henry's law can be described for the solid, fluid and gas threephase mixture as

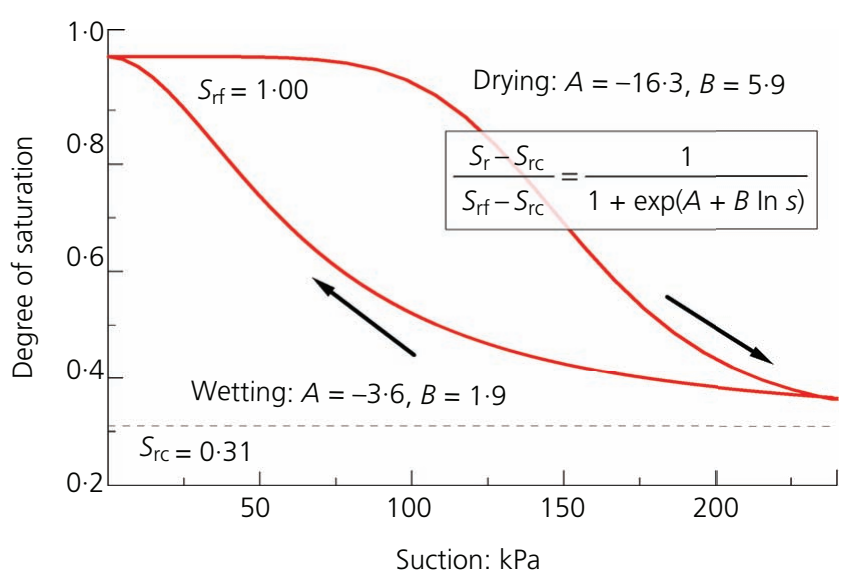

Figure 16. Soil-water retention curves used in computation 


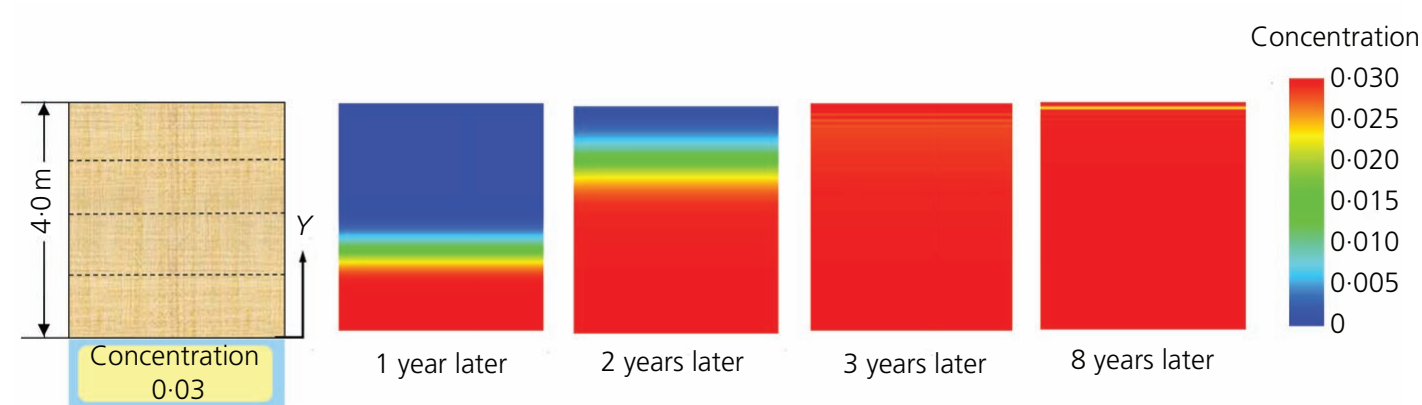

(a)

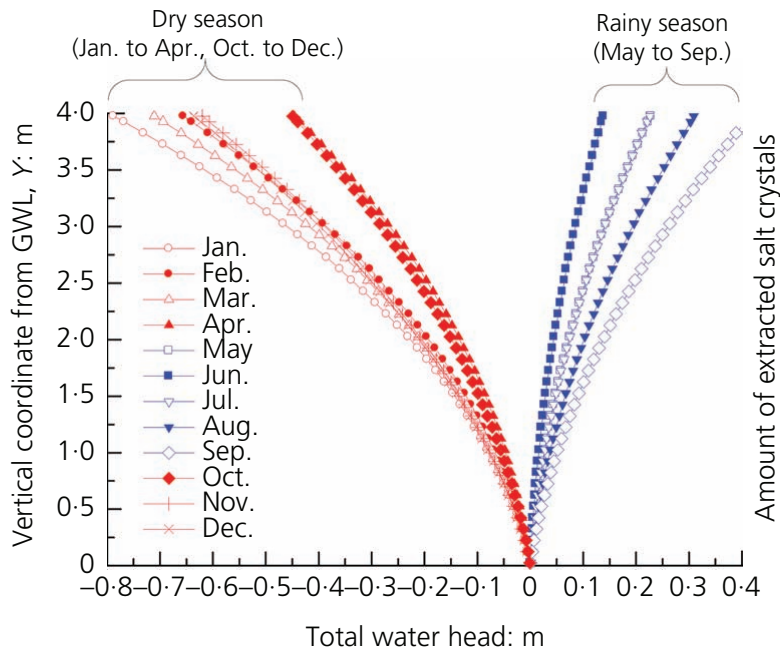

(b)

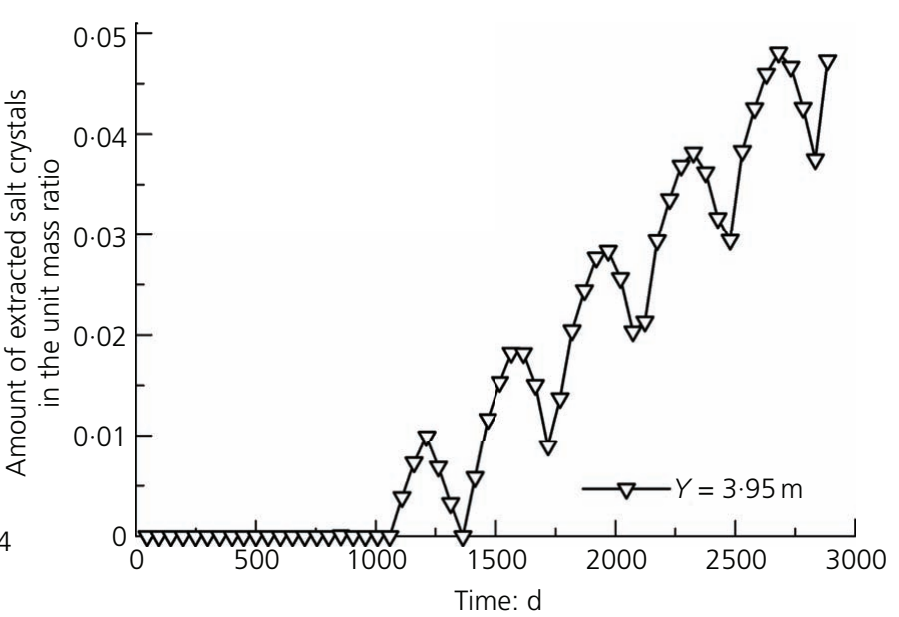

(c)

Figure 17. Computed results of salt damage: (a) development of salt concentration in the ground; (b) change of total water head distribution; (c) accumulation of salt crystals near the ground surface. GWL, groundwater level

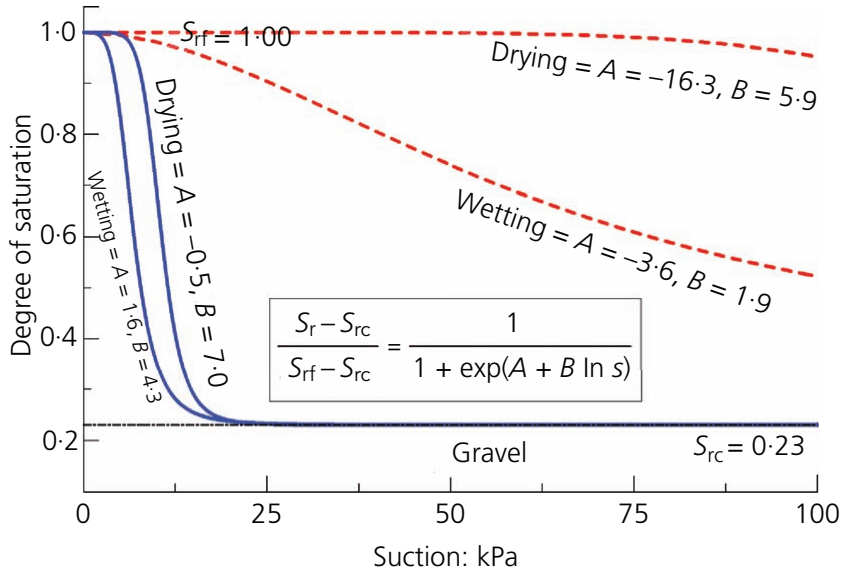

Figure 18. SWRCS of gravel
19. $m_{\mathrm{dg}}=k_{\mathrm{h}} p_{\mathrm{g}} V_{\mathrm{w}}$

in which $p_{\mathrm{g}}$ is the gas pressure $(\mathrm{kPa}) ; k_{\mathrm{h}}$ is Henry's constant (mol/ $\left.\left(\mathrm{m}^{3} \mathrm{kPa}\right)\right) ; m_{\mathrm{dg}}$ is the dissolved gas mass $(\mathrm{g})$; and $V_{\mathrm{w}}$ is the volume of the liquid phase $\left(\mathrm{m}^{3}\right)$. Then, the density of dissolved air is expressed from Equation 19 as

20. $\rho_{\mathrm{dg}}=\frac{m_{\mathrm{dg}}}{V_{\mathrm{w}}}=k_{\mathrm{h}} p_{\mathrm{g}}$

where $\rho_{\mathrm{dg}}$ is the density of the substantial part of the air dissolved in the liquid phase and $\bar{\rho}_{\mathrm{dg}}$ is the density of the dissolved air per unit volume of the unsaturated soil. Since $\bar{\rho}_{\mathrm{dg}}=n S_{\mathrm{r}} \rho_{\mathrm{dg}}$, the mass conservation law of dissolved air and pore air contained in the unsaturated soil is described as

21. $\left(\dot{\bar{\rho}}_{\mathrm{g}}+\bar{\rho}_{\mathrm{g}} \operatorname{div} v_{\mathrm{g}}\right)+\left(\dot{\bar{\rho}}_{\mathrm{dg}}+\bar{\rho}_{\mathrm{dg}} \operatorname{div} v_{\mathrm{w}}\right)=0$ 
Extension of unsaturated soil mechanics

\section{and its applications}

lizuka, Tachibana, Takeyama et al.
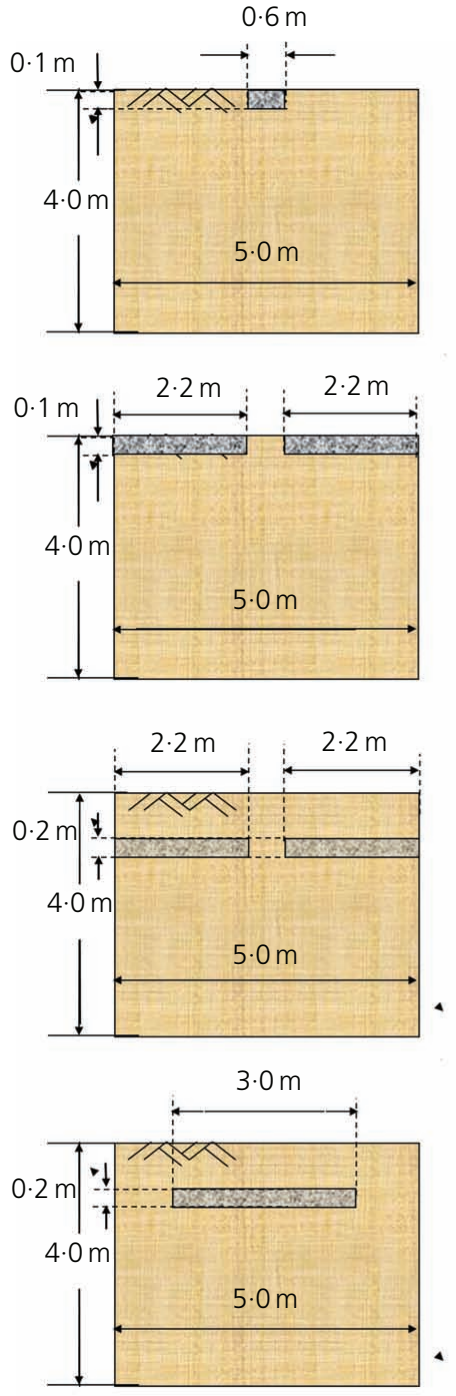

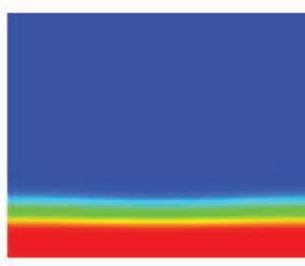

1 year later

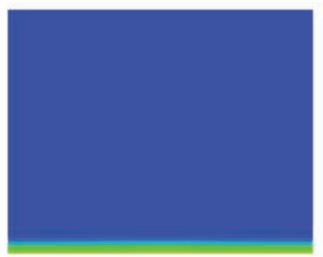

1 year later

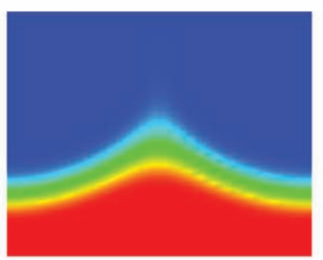

1 year later

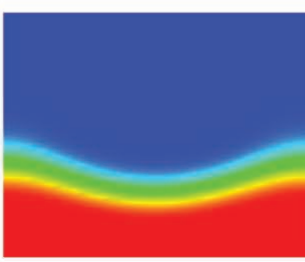

1 year later

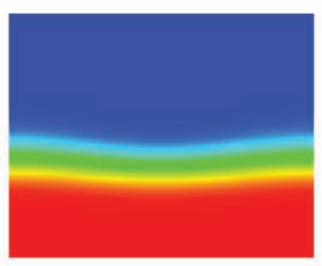

2 years later

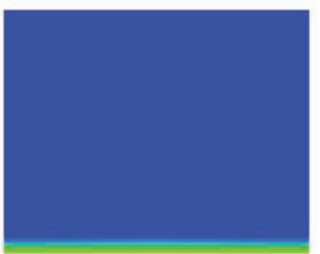

2 years later

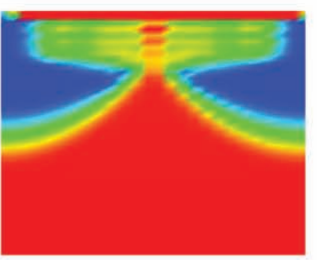

2 years later

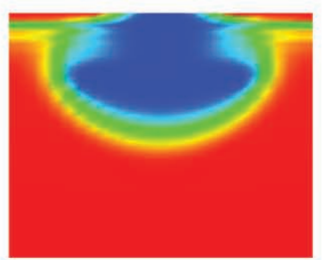

2 years later

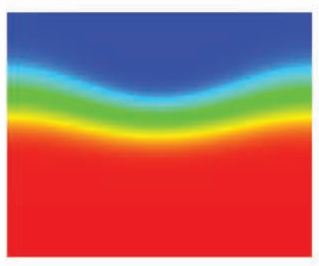

3 years later

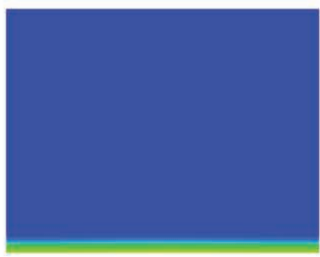

3 years later
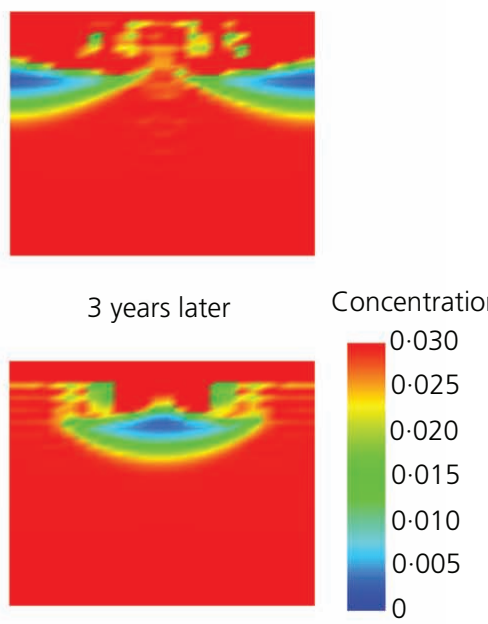

3 years later

Figure 19. Computed results of mulching effects

Substituting $\bar{\rho}_{\mathrm{g}}=n\left(1-S_{\mathrm{r}}\right) \rho_{\mathrm{g}}$ and $\bar{\rho}_{\mathrm{dg}}=n S_{\mathrm{r}} \rho_{\mathrm{dg}}$ into Equation 21 , the following is obtained

$$
\begin{aligned}
& (1-n) \operatorname{div} v_{\mathrm{s}}\left(1-S_{\mathrm{r}}\right)-n \dot{S}_{\mathrm{r}}+n\left(1-S_{\mathrm{r}}\right) \frac{\dot{\rho}_{\mathrm{g}}}{\rho_{\mathrm{g}}} \\
& +n\left(1-S_{\mathrm{r}}\right) \operatorname{div} v_{\mathrm{g}}+\left[(1-n) \operatorname{div} v_{\mathrm{s}} S_{\mathrm{r}} \frac{\rho_{\mathrm{dg}}}{\rho_{\mathrm{g}}}+n \dot{S}_{\mathrm{r}} \frac{\rho_{\mathrm{dg}}}{\rho_{\mathrm{g}}}\right. \\
& \text { 22. } \left.\quad+n S_{\mathrm{r}} \frac{\dot{\rho}_{\mathrm{dg}}}{\rho_{\mathrm{g}}}+n S_{\mathrm{r}} \frac{\rho_{\mathrm{dg}}}{\rho_{\mathrm{g}}} \operatorname{div} \boldsymbol{v}_{w}\right]=0
\end{aligned}
$$

Therefore, the continuity equation is expressed from Equation 22 using $\rho_{\mathrm{dg}} / \rho_{\mathrm{g}}=k_{\mathrm{h}}\left(R T / M_{\mathrm{m}}\right)=A_{\mathrm{dg}}$ as

$$
\begin{aligned}
& -\left(1-S_{\mathrm{r}}+A_{\mathrm{dg}} S_{\mathrm{r}}\right) \dot{\varepsilon}_{\mathrm{v}}-\left(1-A_{\mathrm{dg}}\right) n \dot{S}_{\mathrm{r}} \\
& \text { 23. }+\left[\frac{n\left(1-S_{\mathrm{r}}\right)+A_{\mathrm{dg}} n S_{\mathrm{r}}}{p_{\mathrm{g}}+p_{\mathrm{a}_{0}}}\right] \dot{p}_{\mathrm{g}}+\operatorname{div} \widetilde{\boldsymbol{v}}_{\mathrm{g}}+A_{\mathrm{dg}} \operatorname{div} \widetilde{\boldsymbol{v}}_{\mathrm{w}}=0
\end{aligned}
$$

Equation 23 provides a governing equation as the continuity condition in the soil, water and air coupling problem, considering Henry's law. With this, the compressible seepage equation in 
Extension of unsaturated soil mechanics

and its applications

lizuka, Tachibana, Takeyama et al.
Figure 4 is replaced by Equation 23. Here, $\rho_{\mathrm{g}}$ is the density of pore air (gas); $p_{\mathrm{a}_{0}}$ is the atmospheric pressure; $M_{\mathrm{n}}$ is the material molar mass $(\mathrm{g} / \mathrm{mol}) ; R$ is the gas constant $(\mathrm{J} /(\mathrm{K} \mathrm{mol})) ; T$ is the absolute temperature $(\mathrm{K})$; $\widetilde{\boldsymbol{v}}_{\mathrm{w}}$ is the relative velocity of pore water $\left(=n S_{\mathrm{r}}\left(\boldsymbol{v}_{\mathrm{w}}-\right.\right.$ $\left.\left.\boldsymbol{v}_{\mathrm{S}}\right)\right) ; \widetilde{\boldsymbol{v}}_{\mathrm{g}}$ is the relative velocity of pore gas $\left(=n\left(1-S_{\mathrm{r}}\right)\left(\boldsymbol{v}_{\mathrm{g}}-\boldsymbol{v}_{\mathrm{s}}\right)\right)$; and $v_{\mathrm{s}}, \boldsymbol{v}_{\mathrm{w}}$ and $\boldsymbol{v}_{\mathrm{g}}$ are the velocity of the solid phase, the velocity of the fluid phase and the velocity of the gas phase, respectively.

As a demonstration, the soil sampling from the ocean floor is considered. Even in the usual sampling from soils on land, the effect of vaporisation of dissolved gas on the soil specimens has been noted - for example, in the publications by Fujishita (1965), Matsumoto et al. (1969) and Tsui and Helfrich (1983). In the case of soil sampling from the deep ocean floor, the influence of vaporisation of the gas dissolved in the pore water on the desaturation and the effective stress change in the soil specimens cannot be ignored. In this example, this influence is examined through numerical simulations following the paper by Sugiyama et al. (2018). Here, Henry's constant, $k_{\mathrm{h}}$, is estimated using dissolved pore water gas data obtained from the Okhotsk seafloor and reported by Yamashita et al. (2013, 2014). The input parameters used in the computation are shown in Table 1.

Figure 20 summarises the sampling process, which is divided into two phases. One is the process of uplifting the core barrel (process 1), and another is the process of extrusion of the soil specimen from the core barrel (process 2). The mechanical disturbance in process 2 due to trimming and moulding of the specimen is out of scope here. In process 1, the lateral deformations of the soils are fixed as boundary conditions and both the upper and lower edges of soils in the core barrel, the length of which is assumed to be $1.0 \mathrm{~m}$, are released under permeable conditions for both pore water and pore air to balance with the atmosphere. In process 2 , every element extruded from the core barrel is unloaded by applying external forces to simulate the stress release to balance with the atmosphere $(101 \cdot 3 \mathrm{kPa})$. Here, since process 2 is considered to occur rapidly compared to process 1 , impermeable boundaries are assumed for both pore water and pore air. After process 2, the soil specimen is subjected to a shear test (process 3), in which the stress state after process 2 gives the initial condition for the strength testing of the specimen.

Figure 21 indicates the distributions of the degree of saturation and the residual effective stress ratio in the soil sample in the core

\section{Table 1. Input parameters used in computation}

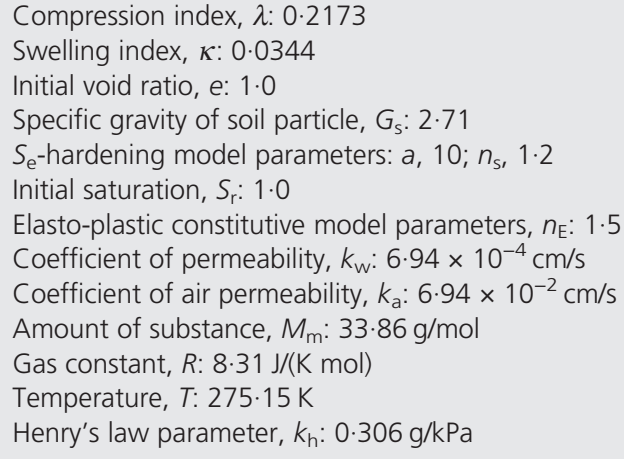

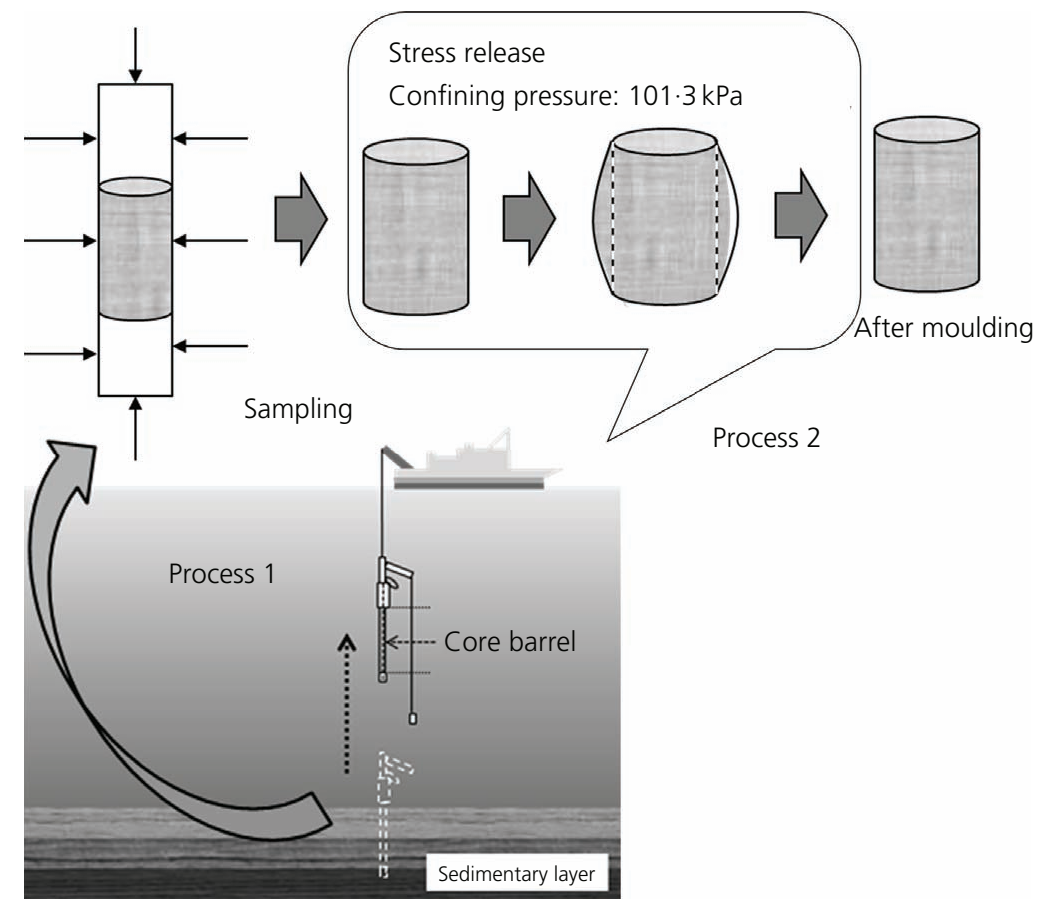

Figure 20. Considered processes accompanying sampling 

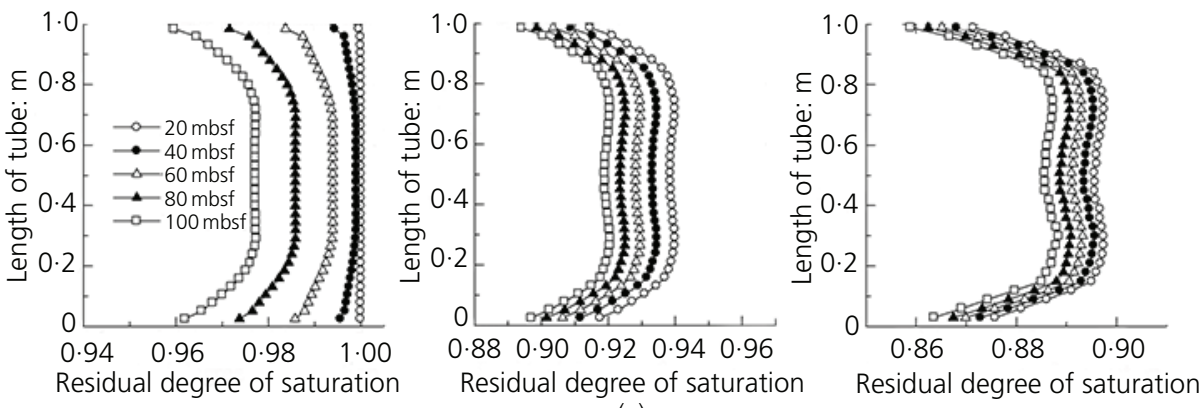

(a)
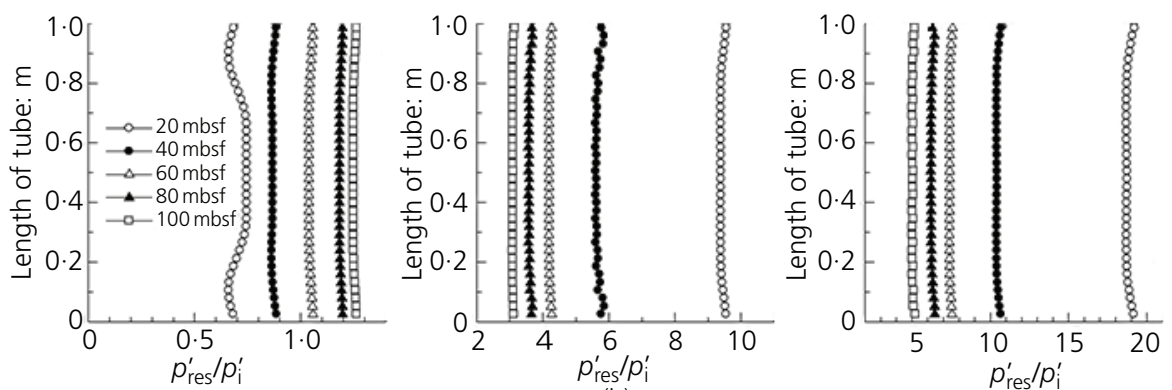

Figure 21. Computed distribution of remaining stress: (a) residual degree of saturation; (b) residual effective stress ratio

barrel after process 1 , in which $p_{\text {res }}^{\prime}$ is the residual effective mean stress and $p_{\mathrm{i}}^{\prime}$ is the in situ effective mean stress. The computed cases of sampling from seafloor with a depth of $0 \mathrm{~m}$ (equivalent to sampling soil from on land), seafloor with a depth of $200 \mathrm{~m}$ and seafloor with a depth of $400 \mathrm{~m}$ are compared, in which the unit 'mbsf' indicates 'metres below seafloor'. Five cases of sampling from a depth of $20 \mathrm{mbsf}$ for every $20 \mathrm{~m}$ down to a depth of $100 \mathrm{mbsf}$ under seafloor are also compared in each figure. Figure 21(a) shows that desaturation due to the vaporisation of dissolved gas prominently develops in sampling from the deep seafloor. In contrast, this desaturation is not remarkable in the cases of sampling from the relatively shallow ground under the seafloor at $0 \mathrm{~m}$ depth. Figure 21(b) also shows that the residual effective stress ratio becomes much larger than $1 \cdot 0$, except in cases of sampling from the relatively shallow ground under the seafloor at
$0 \mathrm{~m}$ depth. Suction develops greatly with desaturation, and, subsequently, the residual effective stress exceeds the initial in situ effective stress. The suction development at the centre of the specimen during process 1 is shown in Figure 22, which compares the cases of sampling from seafloors with depths of 0 and $200 \mathrm{~m}$. The amount of suction increase due to desaturation with uplifting of the core barrel is considerably large in the cases of deeper sampling from the seafloor and sampling from deeper seafloor.

In process 2 , since the specimen is extruded from the core barrel and is exposed to the atmosphere, it experiences stress release, resulting in a decrease in the residual effective stress with deformation. The effective stress change during process 2 is shown in Figure 23, in which process 3, used as a reference in the figure, is the shear process to determine strength, such as used in an
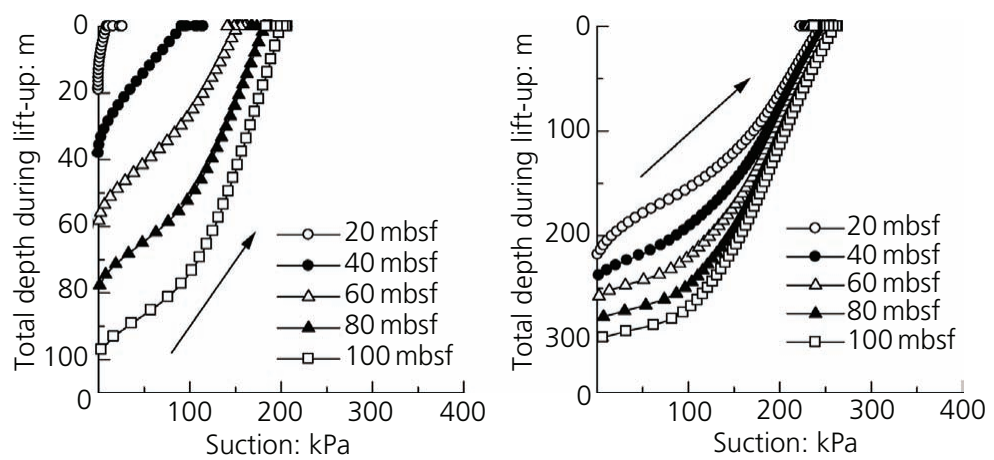

Figure 22. Suction change during process 1 

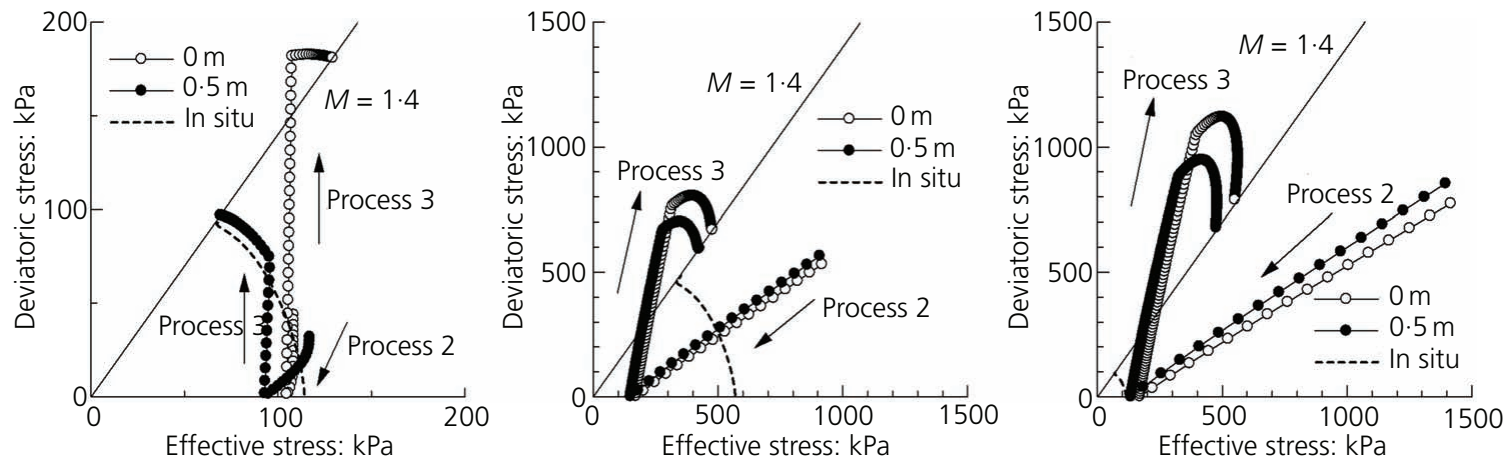

Figure 23. Effective stress change of specimen in process 2

unconsolidated-undrained test. The three cases of sampling from a depth of $20 \mathrm{mbsf}$ under the seafloor with a depth of $0 \mathrm{~m}$ (case 1), sampling from a depth of $100 \mathrm{mbsf}$ under the seafloor with a depth of $0 \mathrm{~m}$ (case 2) and sampling from a depth of $20 \mathrm{mbsf}$ under the seafloor with a depth of $200 \mathrm{~m}$ (case 3) are compared, in which the effective stresses in the elements positioned at the centre of the core barrel $(0.5 \mathrm{~m})$ and at the tip of it $(0 \mathrm{~m})$ are shown. Here, 'In situ' in the figure indicates the ideal case that the soil element is sheared without any sampling disturbance during processes 1 and 2 . The residual effective stresses greatly decrease during process 2 in the cases of deeper sampling from the seafloor (case 2) and sampling from deeper seafloor (case 3). Such decrease in the residual effective stress brings about an overconsolidated state in the specimen. The increase in suction due to desaturation, as shown in Figure 22, and the decrease in residual effective stress due to the stress release, as shown in Figure 23, determine the effective stress state in the specimen after the sampling process. In the cases of deeper sampling from the seafloor and sampling from deeper seafloor, the computation results show that, since the decrease in the residual effective stress is greater than the increase in suction due to desaturation, the specimen becomes heavily overconsolidated. However, in the case of sampling from shallow seafloor with a depth of $0 \mathrm{~m}$ (equivalent to sampling on land, as seen in case 1 of Figure 23), desaturation and overconsolidation of the specimen at the centre of the core barrel $(0.5 \mathrm{~m})$ do not occur markedly, and both are balanced, which possibly results in an appropriate in situ strength. Although it is necessary to confirm the effective stress changes discussed in this paper through measurement and monitoring, such a large effective stress change is predicted by introducing Henry's law in the case of sampling from deep seafloor.

\section{Application case 4: access to liquefaction problems of unsaturated soil}

According to reports from surveys and boring data taken at areas of lesser degree of liquefaction after events such as the 1964 Niigata earthquake and the 1995 Kobe earthquake (Great Hanshin-Awaji earthquake) occurred, the lesser liquefaction can be attributed to a de-amplified effect arising from the unsaturated state, which increases the liquefaction strength (strength against liquefaction), according to Nishigaki et al. (2008). Chaney (1978), Yoshimi et al.
(1989) and others have also pointed out that liquefaction strength increases as the degree of saturation decreases. In this section, analytical techniques are presented that can quantitatively examine the effect of the degree of saturation on liquefaction strength. The extended $S_{\mathrm{e}}$-hardening model introduced in the section headed 'The constitutive model employed in the deformation problem' with consideration of subloading surface and rotational hardening (Equations 10-15) is employed and the soil, water and air coupling computations are carried out under cyclic loading conditions leading to liquefaction. Constitutive parameters of an assumed sandy soil used in the computation are listed in Table 2. The SWRC curve, considering hysteresis loops between the wetting and drying processes, is also assumed as shown in Figure 24. The repeated loading with an amplitude axial strain of 5\% is applied to the soil element under constant lateral pressure and impermeable conditions for both pore water and pore air. Two cases of initial degrees of saturation of 90 and $100 \%$ are compared in Figures 25 and 26. In the case of saturated soil, the average effective stress reaches almost $0.0 \mathrm{kPa}$ at the fourth iteration, whereas it seems that the unsaturated soil retains the effective stress, even when repeatedly loaded ten times. Figures 27 and 28 show the effect of the difference in the degree of saturation on suction (Figure 27) and excess pore water development (Figure 28). The degree of

Table 2. Constitutive parameters used in seismic computation

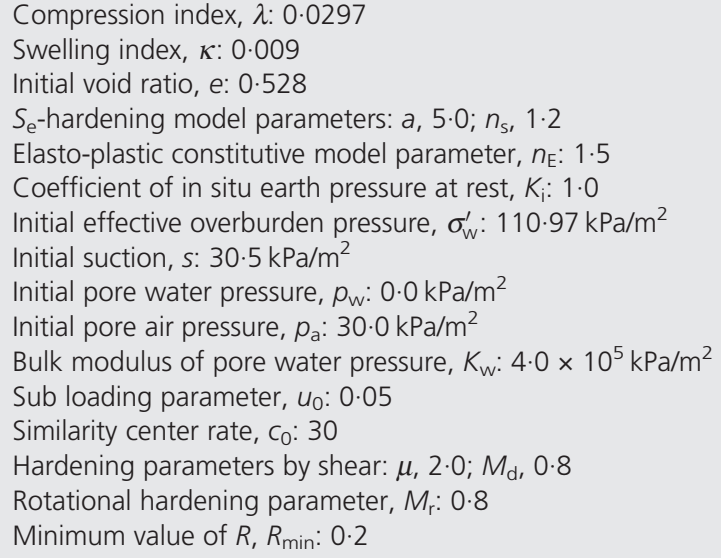




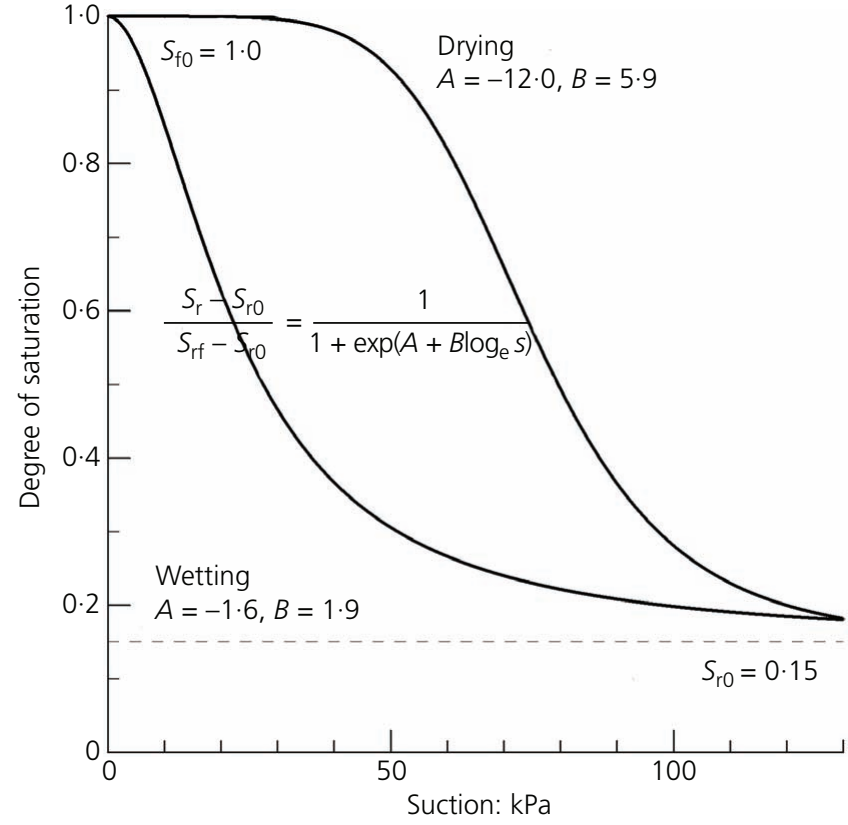

Figure 24. SWRC curve used in computation saturation converges to a certain value (Figure 27), and the effective stress never becomes zero because the suction remains present. Also, as seen in Figure 28, the excess pore water pressure converges at the sixth loading cycle, regardless of the degree of saturation. Okamura and Soga (2006) and Kazama et al. (2006) proposed that the liquefaction in unsaturated ground occurs when the pore air pressure becomes equal to the initial effective stress. Figure 29 shows the changes in effective mean stress and pore air pressure with cyclic loading, compared with the initial effective stress, as indicated by the broken line in the figure. It is found that the pore air pressure exceeds the initial effective stress when the effective mean stress converges to a non-zero constant value. The aforementioned liquefaction condition seems to underestimate the liquefaction strength of the unsaturated ground.

\section{Concluding remarks}

In this paper, case studies intended to expand the applicability of unsaturated soil mechanics are introduced. The theoretical structure of soil, water and air coupling analysis is discussed as a core system of unsaturated soil mechanics. In general, the governing equation of the soil, water and air coupling problem is thought to be derived deductively from the mixture theory, but it should be noted that assumptions particular to soil mechanics are

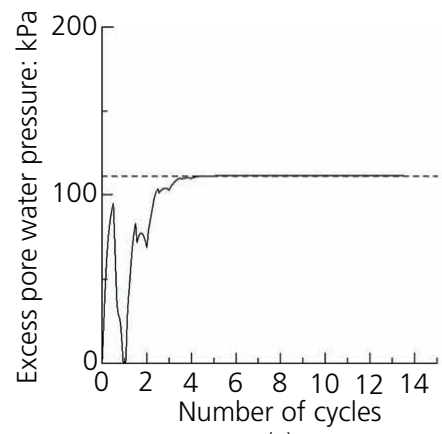

(a)

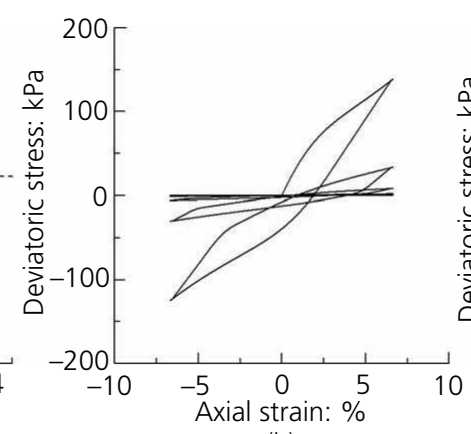

(b)

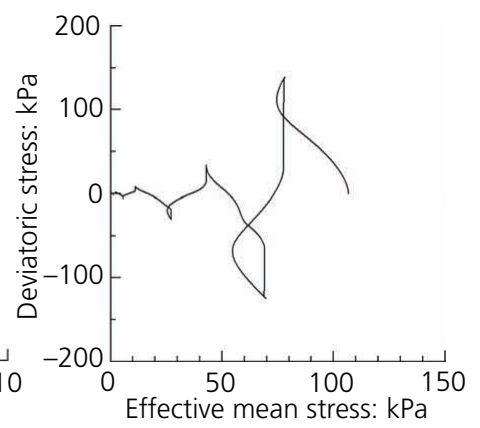

(c)

Figure 25. Seismic response in the case of saturated soil, $S_{r}=1 \cdot 0$ : (a) excess pore water pressure; (b) stress and strain response; (c) effective stress path

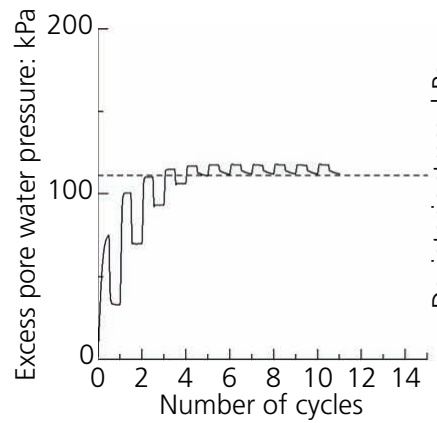

(a)

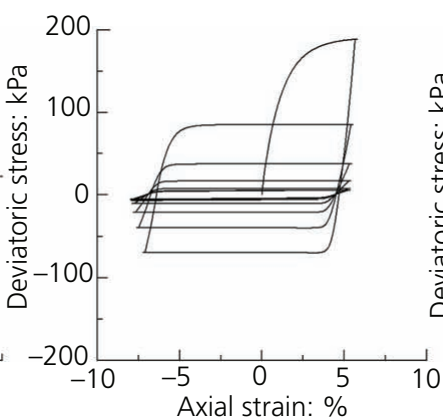

(b)

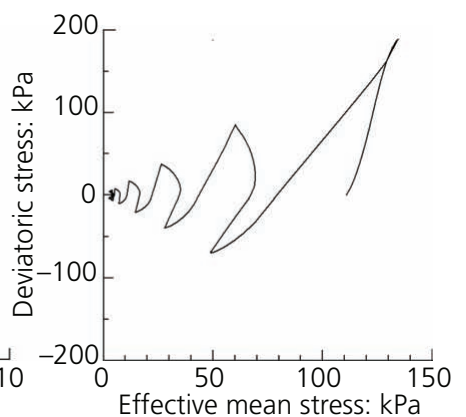

(c)

Figure 26. Seismic response in the case of unsaturated soil, $S_{r}=0 \cdot 9$ : (a) excess pore water pressure; (b) stress and strain response; (c) effective stress path 
Extension of unsaturated soil mechanics

and its applications

lizuka, Tachibana, Takeyama et al.

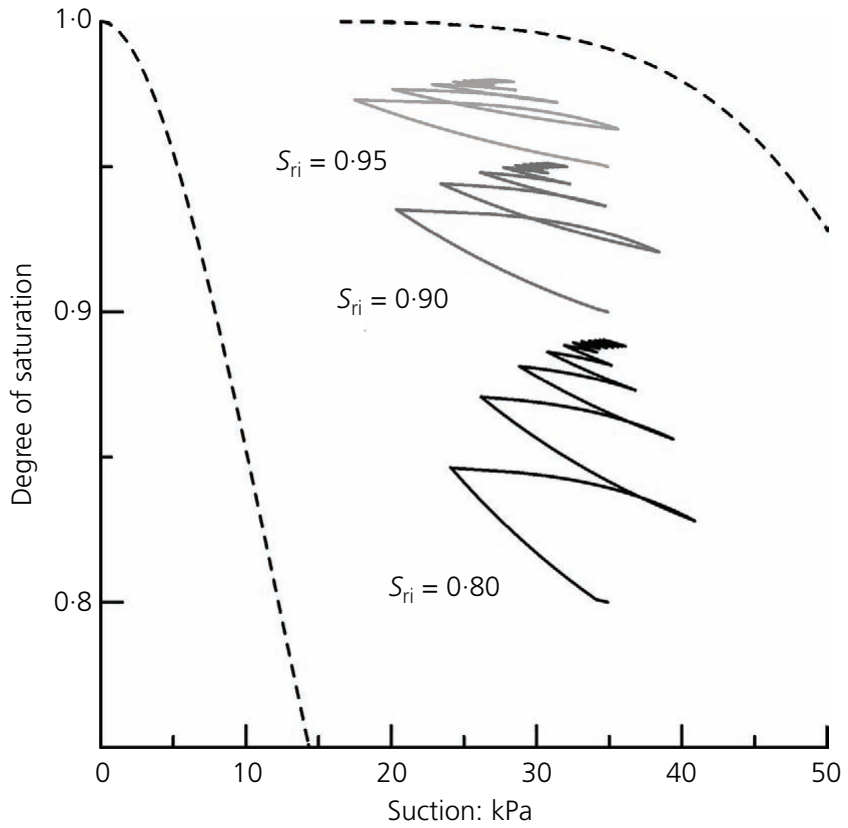

Figure 27. Suction and degree of saturation

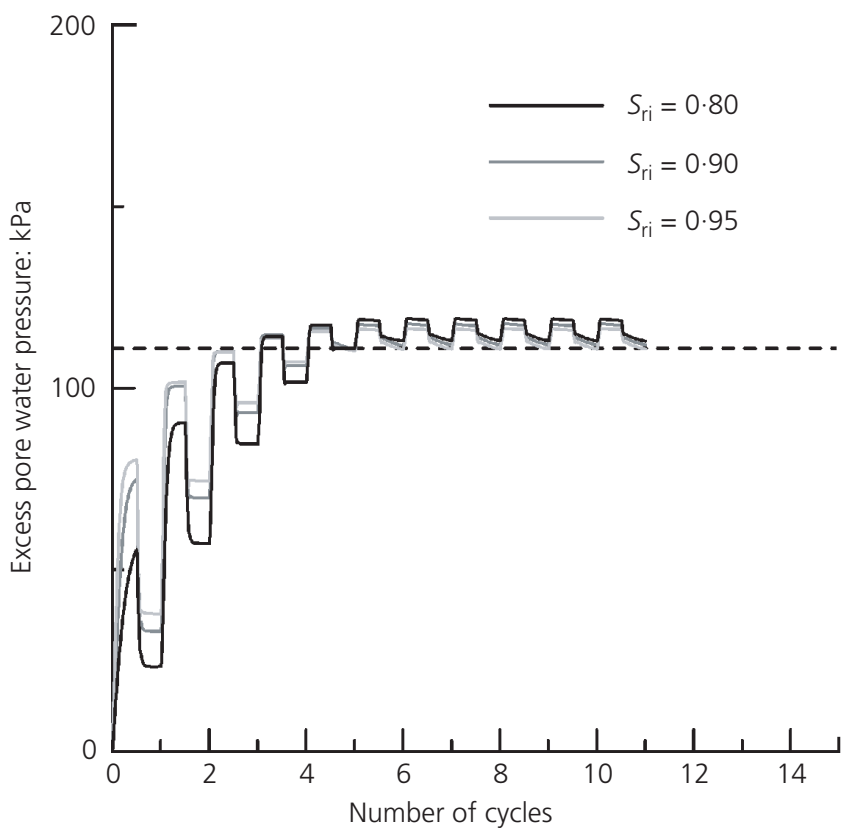

Figure 28. Excess pore water pressure development

employed in its derivation. In addition, the soil, water and air coupling problem is composed of a deformation problem and two seepage problems, with the SWRCs playing the role of a mediator between them. The mechanical properties of soils are all aggregated into a constitutive expression in the deformation problem. By clarifying the theoretical structure in this way, an extension of the theory can be easily made.

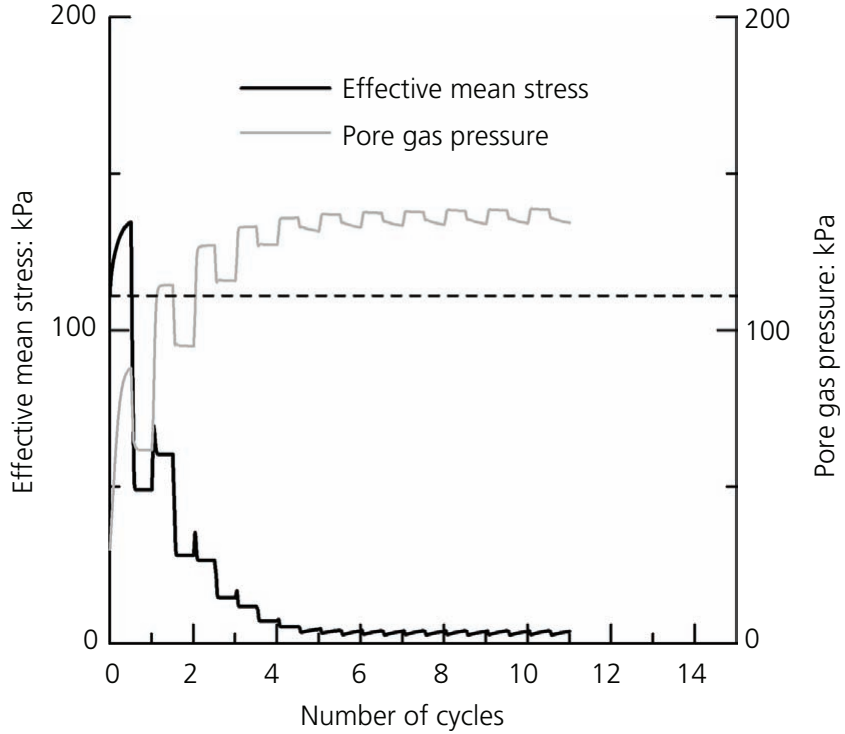

Figure 29. Effective stress and pore air pressure, $S_{r}=0.9$

In this paper, some application examples, which extend the soil, water and air coupling formulations, are presented. In considering the influence of vegetation (see the section headed 'Application case 1: differential settlement due to planting'), major modification of the theoretical formulation is not necessary, indicating that water absorption, rainfall and evaporation due to vegetation can be handled as boundary conditions. In consideration of advection and diffusion of substances dissolved in an unsaturated soil (see the section headed 'Application case 2: consideration of the dissolution, advection and diffusion of a substance in pore water'), the seepage equation of pore water is simply replaced by the extended continuity equation and the diffusion equation. As an example, the possible salt damage caused by rainfall and evaporation, as accompanied by climatic conditions and when the groundwater contained the dilute salt, is presented. In the problem of desaturation due to vaporisation of the gas dissolved in the pore water (see the section headed 'Application case 3: consideration of pore air solution'), the seepage equation for pore air is replaced by the seepage equation considering Henry's law. As an example, the state change of the soil specimen due to desaturation associated with sampling from the deep ocean floor is discussed. In this case, the effective stress state in the soil specimen after the sampling process is much influenced by the increase in suction due to desaturation and the decrease in residual effective stress due to stress release. In the section headed 'Application case 4: access to liquefaction problems of unsaturated soil', an approach to dynamic problems is presented. As an example, the liquefaction resistance of unsaturated soils is numerically examined. The examination in this section is made at the element level under the strain (displacement) control, in which the constitutive equation is numerically solved simultaneously with the continuity conditions and the SWRC equation using the finite-element computation technique. 
The authors hope that unsaturated soil mechanics goes beyond geotechnical engineering and will be widely used in many other fields.

\section{Acknowledgement}

The authors acknowledge Dr Katsuyuki Kawai, associate professor of Kinki University, for his contribution to the research results mentioned in this paper.

\section{REFERENCES}

Alonso EE, Gens A and Josa A (1990) A constitutive model for partially saturated soils. Géotechnique 40(3): 405-430, https://doi.org/10.1680/ geot.1990.40.3.405.

Bishop AW (1960) The measurement of pore water pressure in the triaxial test. In Pore Water Pressure and Suction in Soil. Butterworths, London, UK, pp. 38-46.

Brooks RH and Corey AT (1964) Properties of porous media affecting fluid flow. Journal of the Irrigation and Drainage Division 72(2): 61-88.

Campbell GS (1987) Soil water potential measurement. Proceedings of the International Conference on Measurement of Soil and Plant Water Status, Logan, UT, USA, vol. 1, pp. 115-119.

Castro G (1969) Liquefaction of Sands. PhD thesis, Harvard University, Cambridge, MA, USA.

Chaney RC (1978) Saturation effects on the cyclic strength of sand. Proceedings of the Conference on Earthquake Engineering and Soil Dynamics, Pasadena, CA, USA, vol. 1, pp. 342-358.

Cui YJ and Sun DA (2009) Constitutive modelling: from isothermal to non-isothermal behavior of unsaturated soils. In Unsaturated Soils: Theoretical and Numerical Advances in Unsaturated Soil Nechanics (Buzzi O, Fityus SG and Sheng D (eds)). CRC Press, Boca Raton, FL, USA, pp. 493-506.

de Boer R (1998) Theory of porous media - past and present. Zeitschrift für Angewandte Mathematik und Mechanik 78(7): 441-446.

Fredlund DG and Xing A (1994) Equations for the soil-water characteristic curve. Canadian Geotechnical Journal 31(3): 521-532.

Fujishita T (1965) Rebound of saturated clay on removal of confining pressure. Report of Port and Harbour Technical Research Institute Ministry of Transportation, Japan 4(1): 47-60.

Gens A (1996) Constitutive modelling: application to compacted soils. In Unsaturated Soils: Proceedings of the First International Conference on Unsaturated Soils, UNSAT '95 (Alonso EE and Delage P (eds)). Balkema, Rotterdam, the Netherlands, vol. 3, pp. 1179-1200.

Gens A, Guimaras LDN, Sanchez M and Sheng D (2008) Developments in modelling the generalized behavior of unsaturated soils. In Unsaturated Soils: Advances in Geo-engineering (Toll DG, Augarde CE, Gallipoli D and Wheeler SJ (eds)). CRC Press, Boca Raton, FL, USA, pp. 53-62.

Hashiguchi K (1980) Constitutive equations of elastoplastic materials with elastic-plastic transition. Journal of Applied Mechanics 47(2): 266-272.

Hashiguchi K (1989) Subloading surface model in unconventional plasticity. International Journal of Solids and Structure 25(8): 917-945.

Hashiguchi K and Chen ZP (1998) Elastoplastic constitutive equations of soils with the subloading surface and the rotational hardening. International Journal for Numerical and Analytical Methods in Geomechanics 22(3): 197-227.

Hori M, Ichimura T and Oguni K (2006) Integrated earthquake simulation, estimation of strong ground motions and structural response. Bulletin of the Earthquake Research Institute, University of Tokyo 81: 331-339.

lizuka A and Tachibana S (2017) TC106 General report: unsaturated soils. In Proceedings of the 19th International Conference on Soil Mechanics and Geotechnical Engineering (Lee W, Lee JS, Kim HK and Kim DS (eds)). ISSMGE and Korean Geotechnical Society, Seoul, South Korea, pp. 1113-1121.

Jommi C (2013) General report of TC106. Proceedings of the 18th International Conference on Soil Mechanics and Geotechnical Engineering, Paris, France, pp. 1061-1068.

Kato S (1998) Deformation characteristics of a compacted clay in collapse under isotropic stress state and its shear deformation after collapse. Proceedings of the Japan Society of Civil Engineers 596(43): 271-281.

Kawai K, lizuka A, Hayakawa E and Wang W (2007a) Non-uniform settlement of compacted earth structures caused by the deformation characteristics of unsaturated soil on wetting. Soils and Foundations 47(2): 195-206.

Kawai K, lizuka A, Shimonaga K and Tachibana S (2007b) The influences of uptake of vegetation on the ground. Journal of Applied Mechanics 10: $375-382$.

Kawai K, Yamada R, lizuka A, Tachibana S and Ohno S (2008) Influence of vegetation uptake on the deformation of ground. Journal of Applied Mechanics 11: 443-450.

Kazama M, Takamura H, Unno T, Sento N and Uzuoka R (2006) Liquefaction mechanism of unsaturated volcanic sandy soils. Proceedings of the Japan Society of Civil Engineers, Division C (Geotechnical Engineering) 62(2): 546-561.

Kohgo Y (2003) Review of constitutive models for unsaturated soils and initial boundary value analysis. In Unsaturated Soils - Geotechnical and Geoenvironmental Issues: Proceedings of the 2nd Asian Conference on Unsaturated Soils (Karube D, Iizuka A, Kato S, Kawai K and Tateyama K (eds)). Japanese Geotechnical Society, Tokyo, Japan, pp. $21-40$.

Kosugi K (1994) Three-parameter lognormal distribution model for soil water retention. Water Resources Research 30: 891-901.

Matsumoto K, Horie H and Okumura T (1969) Studies on boring and sampling of saturated alluvial clays. Report of Port and Harbour Technical Research Institute Ministry of Transportation, Japan 8(2): 3-20.

Mualem Y (1976) A new model for predicting the hydraulic conductivity of unsaturated porous media. Water Resources Research Journal 12(3): 513-522.

Nishigaki M, Komatsu M, Fujii N and Ohuchi M (2008) Experimental study on unsaturated soil using proposed method of injecting air into the ground to increase liquefaction strength. Proceedings of the Japan Society of Civil Engineers, Division C (Geotechnical Engineering) 64(2): 340-352.

Nishimura N (1999) Soil mechanics. In Handbook of Geotechnical Engineering. Japanese Geotechnical Society, Tokyo, Japan, pp. 55-64.

Noda T and Yoshikawa T (2015) Soil-water-air coupled finite deformation analysis based on a rate-type equation of motion incorporating the SYS Cam-clay model. Soils and Foundations 55(1): 45-62.

Nomura S, Kawai K, Kakui S et al. (2011) Transfer model of watersolutable material in saturated/unsaturated ground. Journal of Applied Mechanics 14: 231-240.

Nomura S, Kawai K, Tachibana S and lizuka A (2018) Solute transfer during consolidation based on a solid-fluid-solute coupling model. International Journal for Numerical and Analytical Methods in Geomechanics 42(10): 1172-1196, https://doi.org/10.1002/nag.2787.

Ohno S, Kawai K and Tachibana S (2007) Elasto-plastic constitutive model for unsaturated soil applied effective degree of saturation as a parameter expressing stiffness. Proceedings of the Japan Society of Civil Engineers, Division C (Geotechnical Engineering) 63(4): 1132-1141.

Ohno S, Kawai K, lizuka A et al. (2013) Elasto-plastic constitutive model for unsaturated soils with subloading surface concept. In Geotechnical Predictions and Practice in Dealing with Geohazards (Chu J, Wardani SPR and Iizuka A (eds)). Springer, Dordrecht, the Netherlands, pp. 215-228. 
Okamura M and Soga Y (2006) Effects of pore fluid compressibility on liquefaction resistance of partially saturated sand. Soils and Foundations 46(5): 695-700.

Penman HL (1948) Natural evaporation from open water, bare soil and grass. Proceedings of the Royal Society of London, Series A 193(1032): 454-465.

Sekiguchi H and Ohta H (1977) Induced anisotropy and time dependency in clays. Proceedings of 9th International Conference on Soil Mechanics and Foundation Engineering, Tokyo, Japan, pp. 306-315.

Sheng D (2011) Review of fundamental principles in modelling unsaturated soil behavior. Computers and Geotechnics 38(6): 757-776.

Sheng D and Fredlund DG (2008) Elastoplastic modelling of unsaturated soils: an overview. Proceedings of the 12th International Conference of International Association for Computer Methods and Advances in Geomechanics (IACMAG), Ponda, India, pp. 2084-2105.

Sheng D, Gens A, Fredlund DC and Sloan SW (2008) Unsaturated soils: from constitutive modelling to numerical algorithms. Computers and Geotechnics 35(6): 810-824.

Shibata T (1963) On the volume changes of normally consolidated clays. In Disaster Prevention Research Institute Annuals. Kyoto University, Kyoto, Japan, No. 6, pp. 128-134 (in Japanese).

Shuurman IE (1966) The compressibility of an air/water mixture and a theoretical relation between the air and water pressures. Géotechnique 16(4): 269-281, https://doi.org/10.1680/geot.1966.16.4.269.

Sugiyama Y, Tachibana S, Sakaguchi H and lizuka A (2018) Analytical investigation of disturbance on seabed-sampled soil specimens and its influence on unconfined strength. Soils and Foundations 58(3): 689-701, https://doi.org/10.1016/j.sandf.2018.02.026.

Takeyama T, Tachibana S, Kitanoi T and lizuka A (2019) Application of partitioned iterative coupling approach to multi-physics. Journal of Engineering and Construction 8(1): 13-18.

Tanaka M, Kawai K, Kanazawa S et al. (2010a) Influences of initial and boundary conditions in banking simulation on stress distribution within an embankment. Journal of Applied Mechanics 13: 423-430.
Tanaka M, Kawai K, Kanazawa S et al. (2010b) Banking simulation with a constitutive model for unsaturated soil. Proceedings of the 5th International Conference on Unsaturated Soils, Barcelona, Spain, pp. 1337-1342.

Tatsuoka F (1972) Study on Deformation Characteristics of Sand by Triaxial Tests. Doctoral thesis, University of Tokyo, Tokyo, Japan.

Tsui $Y$ and Helfrich S (1983) Wave-induced pore pressures in submerged sand layer. Journal of Geotechnical Engineering 109(4): 603-618.

Uzuoka R and Borja RI (2012) Dynamic of unsaturated poroelastic solids at finite strain. International Journal for Numerical and Analytical Methods in Geomechanics 36(13): 1535-1573.

van Genuchten MT (1980) A closed-form equation for predicting the hydraulic conductivity of unsaturated soils. Soil Science Society of America Journal 44(5): 892-898.

Wheeler SJ and Karube D (1996) Constitutive modelling. In Unsaturated Soils: Proceedings of the First International Conference on Unsaturated Soils, UNSAT '95 (Alonso EE and Delage P (eds)). Balkema, Rotterdam, the Netherlands, vol. 3, pp. 1323-1356.

Wheeler SJ, Sharma RS and Buisson MSR (2003) Coupling of hydraulic hysteresis and stress-strain behavior in unsaturated soils. Géotechnique 53(1): 41-54, https://doi.org/10.1680/geot.2003.53.1.41.

Wojtasik AT and Jez J (2000) Multistory apartment building on Poznan clay - case history. Proceedings of the 1st Asian Conference on Unsaturated Soils, Singapore, pp. 757-762.

Yamashita S, Takahashi N, Shoji H et al. (2013) Survey Report of Sea Bottom Sediments off Abashiri, Okhotsk Sea (OS249 Survey). Environmental and Energy Resources Research Center, Kitami Institute of Technology, Kitami, Japan, pp. 15-39.

Yamashita S, Takahashi N, Shoji H et al. (2014) Survey Report of Sea Bottom Sediments Off Abashiri, Okhotsk Sea, C263 (OS263 Survey). Environmental and Energy Resources Research Center, Kitami Institute of Technology, Kitami, Japan, pp. 15-35.

Yoshimi Y, Tanaka K and Tokimatsu K (1989) Liquefaction resistance of partially saturated sand. Soils and Foundations 29(3): 157-162.

\section{How can you contribute?}

To discuss this paper, please submit up to 500 words to the editor at journals@ice.org.uk. Your contribution will be forwarded to the author(s) for a reply and, if considered appropriate by the editorial board, it will be published as a discussion in a future issue of the journal. 